Amanda XiaoXuan Chen, B.Sc., Ryerson University, 2010

A Major Research Paper

presented to Ryerson University

in partial fulfillment of the requirements for the degree of

\title{
Master of Planning
}

in

Urban Development

Toronto, Ontario, Canada, 2010*

(c) Amanda XiaoXuan Chen $2010^{*}$ 
I hereby declare that I am the sole author of this major research paper.

I authorize Ryerson University to lend this paper to other institutions or individuals for the purpose of scholarly research.

I further authorize Ryerson University to reproduce this paper by photocopying or by other means, in total or in part, at the request of other institutions or individuals for the purpose of scholarly research. 
(C) Amanda XiaoXuan Chen, 2010

Master of Planning

in

Urban Development

Ryerson University

\begin{abstract}
This paper conducts an unprecedented research that thoroughly defines the concept of creative hubs as an urban mechanism that emerges from the need of effectively leveraging local resources to better facilitate creative activities and ultimately improve local economies. Building a conceptual framework that articulates the three essential components (the 3Ps) of creative hubs: people, place, and planning, this study further analyzes the creative-hub distribution in the City of Toronto. Using a mapping approach to illustrate how different creative hubs scatter, it is observed that there exist congregations of institutional-level and district-level creative hubs along the north-south and east-west direction respectively in the City of Toronto. Finally, a case study on Liberty Village is conducted to scrutinize how a creative hub achieve its functional value basing on its people, place, and planning policies.
\end{abstract}

Key words: creative cities, creative districts, creative planning 


\section{ACKNOWLEDGEMENTS}

I would like to thank my supervisor Dr. Steven Webber, who is responsible for keeping me on the right track of my research. He was always there to listen and give advice with an open mind. I also thank my second reader, Dr. Beth Moore Milroy, who offered me valuable suggestions and encouraged me to think and critique.

During the course of this study, I was greatly supported by Mr. Jim Herlik and Mr. Ram Naguleswaran from the City of Toronto who kindly provided me with Toronto Employment Survey Statistics. I am also greatly indebted to my interviewees: Dr. Greg Baeker from AuthentiCity, as well as Ms. Lori Martin from The Economic Development \& Culture Division at the City of Toronto. I thank them for giving me the opportunity picking their brains and sharing their professional insights.

Last, but not least, I thank my parents, for giving me life in the first place, for educating me with all different aspects in life, for unconditional support and encouragement to pursue my interests, and most importantly, for reminding me that learning is a life-long process. 


\section{TABLE OF CONTENTS}

1. INTRODUCTION

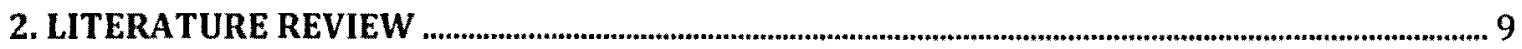

2.1. 'Creativity' in an Urban Context .......................................................................... 9

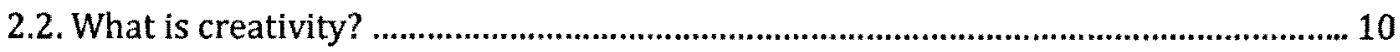

2.3. Operationalize creativity from a human-capital perspective - defining creative

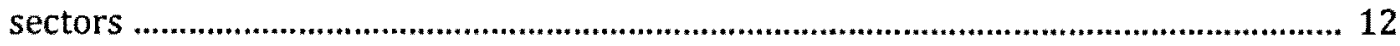

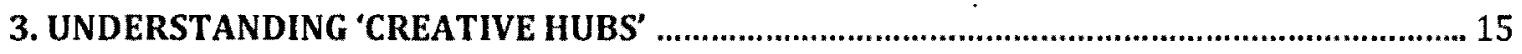

3.1. Agglomeration of Creativity - the underlying rationale ........................................... 16

3.2. Development of Related Terminologies ............................................................... 18

3.3. Major Critiques: Displacement and Gentrification .................................................. 22

3.4. A 3Ps Framework for Defining Creative Hubs - people, place, and planning ............ 23

3.4.1 What function does a creative hub perform? .............................................. 25

3.4.2. What key elements mark a creative hub? ................................................................. 25

3.4.3. What role does planning play during the course of establishing,

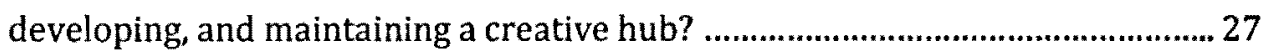

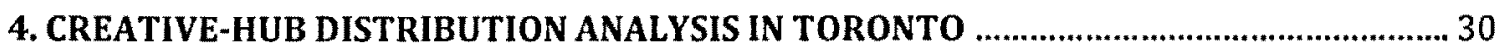

4.1. North-South Direction and Institutional-level Creative hubs Congregation ............. 42

4.2. East-west Direction and District-level Creative hubs Congregation ......................... 43 
5. A CREATIVE HUB CASE STUDY - LIBERTY VILLAGE ............................................................ 47

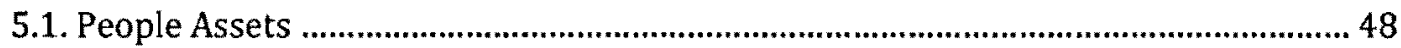

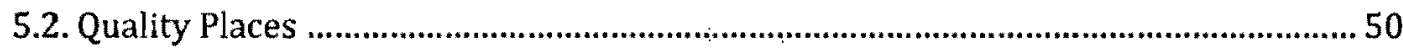

5.3. Planning \& Development ........................................................................................ 52

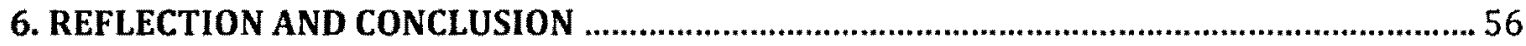

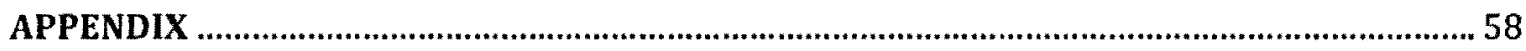

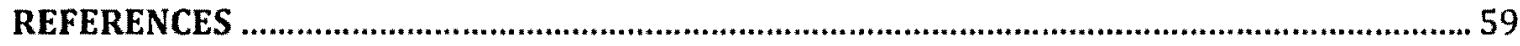




\section{INTRODUCTION}

The emerging trend in the urban economies that we are confronting today indicates the cusp of an era where the generation and creation of wealth is no longer primarily reliant on the production level of agriculture or industrial efficiency. Instead, we are now entering a transformation phase where the exploitation of human creativity and innovation eventually drives our long-term prosperity. In the past decade, the need for reassessing urban resources in terms of seeking ways to unleash creativity and innovation has been discussed from different perspectives at different jurisdictional levels. Recognizing that creativity has become a competitive edge for a region in a way that it drives the primary source of economic values, many cities around the world are gradually considering revisions to existing planning frameworks and implementing of aggressive policies to nurture creative actives. In the report Ontario in the Creative Age (2009), a substantial outlook on Ontario's various opportunities facing the current creative economy is presented. As one of the actions recommended for the Province to thrive in the emerging creative economy, building geographic advantage is proposed:

Our future advantage in the creative age will be based on facilitating and encouraging the geographic clustering and concentration of industries and skills. The increasing spikiness of economic development puts a premium on density within our urban centres and on the velocity of connections across a mega-region and with outlying areas. (p.3)

In order to elaborate on the meaning of "facilitating and encouraging the geographic clustering and concentration of industries and skills", this study focuses on investigating a smaller-scale urban phenomenon - creative hubs - as a basic geographic concentration unit of urban creativity. The purpose of the study is to put forward the concept of creative hubs as an urban mechanism 
that partially emerges spontaneously however with necessary planning intervention from the need of effectively leveraging local resources to better facilitate creative activities and ultimately prosper local economy. Building a conceptual framework that articulates the three essential components (the 3Ps) of creative hubs: people, place, and planning, this study further analyzes the creative-hub distribution in Toronto by using a mapping approach to illustrate how different creative hubs are scattered in the city.

The discussion which follows is in four parts. First, a literature review provides a general background on how to refine the concept of creativity in an urban context and the operationalization of "creative industries" categories including the definition of "creative workers" that are engaged in such sectors. Attention is then drawn to the examination of creative $h u b$ where a compositional framework (a 3Ps framework) is proposed to explore its three major components. Thirdly, the creative-hub distribution in the City of Toronto is discussed using a mapping approach to scrutinize the distribution and functional roles of different creative hubs in Toronto. Using the proposed framework, this section is followed by a case study on Liberty Village - an emerging employment creative hub in the city - to illustrate how the 3ps components contribute to the hub's existence and prosperity. Finally, reflections and conclusions are presented to discuss the findings of this study and what it leads to in the future. 


\section{LITERATURE REVIEW}

This section introduces the theoretical background of creativity for this study in order to establish the foundation of conceptualizing creative $h u b$ - an urban geographic concentration phenomenon - as a planning mechanism. Through conducting this literature review on the determination of urban creativity and justified functional boundaries for defining creative sectors, it is believed that the discussion on the components of creative hubs in later sections will be more in focus and refined.

\section{1. 'Creativity' in an Urban Context}

During the history of civilization, cities have been living containers of urban development. They attract professionals, intellectuals and workers in different specialties with high-efficiency means for communication. They provide a wide range of goods, products, and services to satisfy various needs and produce business trade and exchange opportunities. We are currently entering an era that cities are facing an urban transformation gradually shifting from a manufacturing-focused wealth generation system towards a knowledge-based economy which greatly relies on creativity (Murray and Baeker, 2006). Continuous discussion around urban creativity is directed with a strong recognition of its contribution to a more sustainable economic and social system. Creativity now has become a competitive edge for a city in a way that it drives the primary source of economic values and raises productivity in certain aspects of urban development through pooling innovation and managing investments (Martin and Florida, 2009). 


\subsection{What is creativity?}

Originally introduced to encourage open-mindedness and imagination, the idea of creativity in relation to urban planning emerged during the late 1980 s in western societies and the interest around it has increased dramatically during the last few years at a global scale (Landry, 2000; Rutten, 2005), On one hand, creativity is usually presented in a literal sense, Kalden and Stolk [2005] articulate it as "originally bringing something that is genuinely new and that is considered valuable enough to be added to culture.... Creativity is every action, every idea or every product that changes an existing preserve or turns it into a new one." (p.195). On the other hand, creativity is understood as an idea of discovering the potential in any city to create conditions for people to think, plan, and act with imagination, utilizing personal qualities such as intelligence and inventiveness, promotes the essence of 'creativity' as an ideology that everyone has his/her capacity to think creatively (Kalden and Stolk, 2005; Landry, 2000).

Landry (2006) describes creativity as a latent form of intellectual capital that is the source of innovation. Although its original formulation is greatly legitimized in the artistic and cultural industries based on the latter's power in establishing local identities, Landry (2000) observes the need for a shift from thinking about lifting production volumes and quantity to addressing how to add values, create innovations and increase urban quality.

Similar to Landry, Richard Florida views the theory of creativity as a version of human capital theory but more in a context of regional growth. Florida (2005) points out that the key to the economic growth is to enable and unleash the potential that human beings have in term of creativity under an open culture. He proposes that the measurement of creativity should focus on regional characteristics - known as the " 3 Ts" of economic growth: technology, talent, and tolerance - rather than merely people's education levels. In his point of view, a region's 
creativity level is dependent on its technology development, knowledge-intensiveness, and population diversity.

Carta (2007) summarizes urban creativity in terms of three factors. First, culture, as a city's most distinctive and competitive resource, is considered as the most important factor in enabling urban creativity. As a product of history, culture yet also extends into the future and provides resources for fostering and reinforcing identity. Secondly, communication, as a city's ability to inform and translate different sorts of information - regarding urban culture, regional identity, and facilitating capacity - to its citizens and all users, provides the means for the processes of innovation and diffusion and makes effective use of the technologies.

Communication is crucial to the idea of creativity in the sense that it strives for efficiency realization through mitigating interaction congestion and deterioration. Thirdly, cooperation, as a rising factor that incorporates today's creativity building in the context of multicultural cities, goes beyond tolerance and implies the ability to assemble a series of components, including human intelligence and scientific technology, while focusing action on shared goals and outcomes. Through cooperation, creativity makes a city capable of mobilizing resources such as talents and infrastructure assets not only more effectively, but in the pursuit of a more harmonious and prepared future.

Saris and Brouwer (2005) view creativity as a production factor that cuts through all economic sectors rather than an independent sector such as design, art, or science technology. They depict a three-phase process through which creativity is evolved into a production force. The first phase is inspiration - it is the invention stage where sources of inspiration from society are put in a starter's environment. The second phase is interaction - it is the marketing, application, refining stage that provides opportunities for different sectors to experiment. Finally, 
transaction represents the phase where production chains are eventually linked through creativity.

\subsection{Operationalize creativity from a human-capital perspective - defining creative sectors}

As implied earlier, the contemporary urban economy has shifted its focus to human capital and people talents. Urban theories gradually place the emphasis on how people and creativity generate jobs, innovation, new divisions of cultural consumption, and economic growth (Drucker, 1993; Markusen, 2004; Markusen and King, 2003; Mathur, 1999). Therefore, operationalizing the concepts that are related to creative employment activities is another requirement for explaining urban creativity and later conceptualizing creative hubs. This section thus focuses on defining creative sectors in terms of their industry compositions.

During the past decade, there is no determined definition on the breadth and depth of creative sectors, but several studies provide useful approaches for differentiating sectors based on how creativity is generated.

A study prepared for the European Commission in 2006 by European Affairs - The Economy of Culture in Europe - lays out a general foundation of defining creative sectors based on the proposition that creativity is the key driving force of economic and social development, as well as innovation and cohesion. The following table represents a general delineation of cultural and creative sectors categorized into three circles surrounding a core arts field. Within Circle 2, in particular, it is recognized that culture becomes a creative input in the production of noncultural goods by including activities such as design, architecture, and advertising. By incorporating the scope of culture into creative sector, such categorizations would enable measurements that more accurately address the economic and social impact of creativity. 


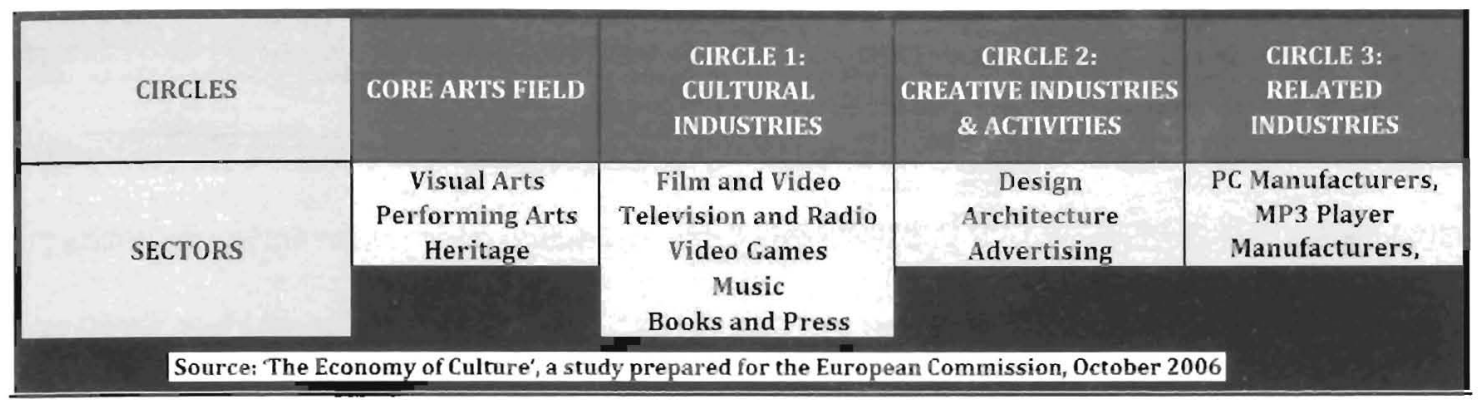

Based on this model, the Work Foundation and National Endowment for Science, Technology and Arts (NESTA) in the UK proposes a framework in its 2007 document Staying Ahead: The economic performance of the UK's creative industries to incornorate the concept of "expressive value" when defining creative sectors. The study discovers that creative industries reverues are largely generated by commercializing a type of "expressive value" - comprising of aesthetic value, spiritual value, social value, historical value, symbolic value, and authenticity value which determines the products' "creative origination".

As a result of using expressive value, the following figure represents $:$ radiation model that maps different layers of creative sectors (as defined in Staying Ahecid: The economic performance of the UK's creative industries, 2007):

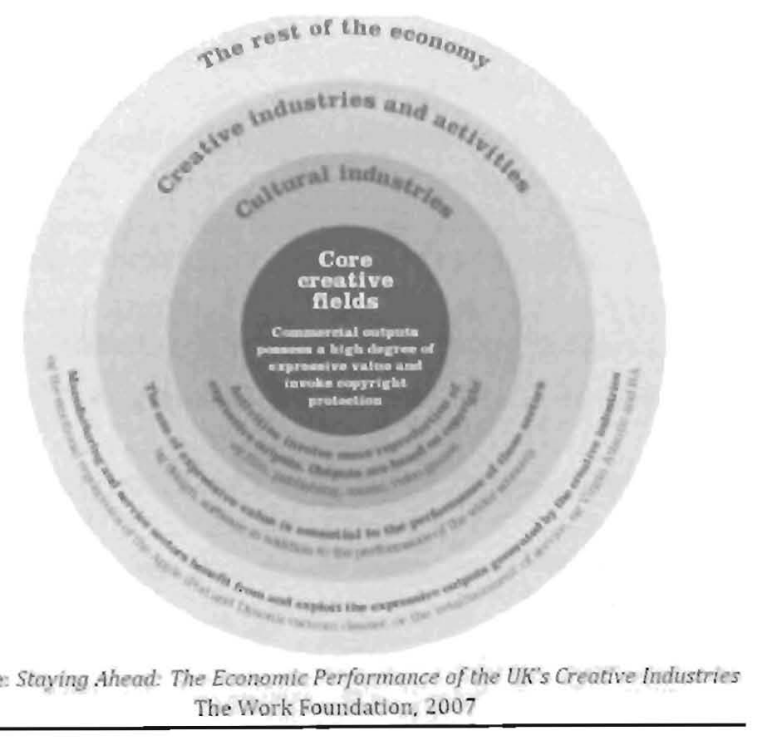


This paper uses the above framework to define creative sectors in the contemporary knowledge and creative economy. Therefore, creative sectors mentioned in later sections can be understood as being structured in terms of four conceptual layers:

\section{- Core creative fields}

This layer consists of commercial outputs that contain high degrees of expressive value and raise copyright protection issues. It includes both originals such as visual arts, artisan crafts, and designs, and experiences such as theatre, dance, music, and heritage.

- Cultural industries

This layer focuses on the creative content producing industries and activities that involve mass reproduction of expressive and copyright-based outputs such as film and television, broadcasting, record companies, book and magazine publishing, computer games and leisure software.

- Creative industries and activities

This layer is based around the use of expressive value, providing creative services to clients, earning revenue through exploiting Intellectual Property that has a high degree of both expressive and functional value. Examples include design consultancies, advertising agencies, architecture practices and digital media firms.

- The rest of the economy

This layer involves all the manufacturing and service sectors that benefit from commercializing the expressive values generated from creative industries. 


\section{UNDERSTANDING 'CREATIVE HUBS'}

Urban theorist Jane Jacobs has a significant influence in describing cities as organic and selforganizing systems rather than robot-like machines designed by engineers. In her famous work The Death and Life of Great American Cities (1961), she wrote:

$$
\begin{aligned}
& \text { Most city diversity is the creation of incredible numbers of different people and } \\
& \text { different private organizations, with vastly differing ideas and purposes, } \\
& \text { planning and contriving outside the framework of public action. The main } \\
& \text { responsibility of city planning and design should be to develop -- insofar as } \\
& \text { public policy and action can do so -- cities that are congenial places for this } \\
& \text { great range of unofficial plans, ideas, and opportunities to flourish. }
\end{aligned}
$$

Under such influence, creativity finds room to survive and thrive. With the prosperity of creative sectors, it is observed that cultural quarters of galleries, clubs, and studios, the right mix of business services, and clusters of high technology activities greatly foster the regional economy and in turn attract in skilled migrants and accommodate them with opportunities to innovate (Hall, 1998).

Rather than jump to the study on how such cultural quarters and innovation clusters ultimately drive the engine of regional economies, this section focuses on the phenomenon of how the agglomeration of creative sectors takes the form of geographic hubs - creative hubs as will be examined later - that emerge and develop to better accommodate the creative activities. Instead of discussing the idea of creative hub purely based on its literal meaning, the following content is divided into three parts. First, it provides a literature review on the rationale and theoretical reasoning behind the manifestation of talents and resources being spatially concentrated. The second part introduces how concepts articulating such phenomenon such as creative quarter, 
convergence centre, and creative milieu are described in different urban contexts and theories. Then, a conceptual framework for creative hubs is generated based on the literature review.

\subsection{Agglomeration of Creativity - the underlying rationale}

From an economic perspective, spatial concentrations of certain economic units and sectors are explained by cluster theories - which are mostly inspired by leading figures of 'agglomeration economies' and 'cluster strategies' including Michael Porter, Alfred Marshall, Kenneth Arrow and Paul Romer. Porter (2004) defines a cluster as "a geographically proximate group of interconnected companies and associated institutions in a particular field, linked by commonalities and complementaries" (p.18). Also asserted by the latter three economists, the benefits of such clustering phenomenon, referred to as 'localisation economies', generate three main types of agglomeration externalities - the Marshal-Arrow-Romer (MAR) externalities (Combes, 2000). First, input externalities are generated from the concentration of producers in a given industry providing incentives for input suppliers to locate nearby. As a result, those producers share specialized services, minimize unnecessary transportation costs, and purchase inputs efficiently. Second, labour market externalities are generated from the creation of pools of specialized workers who acquire cluster-specific skills valuable to the firms and organizations. Also, clusters could improve the functioning of labour market through matching employers and employees more effectively. Third, knowledge externalities are generated from the exchange of information and ideas that are facilitated by cluster amenities. It is considered as a form of organization particularly favourable to technological and knowledge spillovers. Besides these intra-sector externalities proposed by agglomeration economists, it is recognized that geographic concentration may also offer potential inter-sector spillover benefits (Martin et al., 2008). Largely builds his creative city ideologies based on such economic clustering strategies, the well-known creative city thinker Richard Florida (2003) also refers the economic term 
'externality', or 'spillover', as 'co-location' - which articulates the geographic concentration of social and human capital. According to Florida, it is the ability to mobilize talents to form such a concentration of knowledge workers and diverse linkages that cities and regions should develop in order to maintain their competitive advantages in this efficiency-driven economy of the creative age.

Besides agglomeration economies theory, networking capacity is also a major characteristic being described as embodied by creative clusters and milieus. Viewing the nature of networking as a type of 'connectedness', Landry (2006) observes that networking capacity is something intangible and it requires flexible individuals and organizations work with a high degree of trust, self-responsibility and strong principles. From the Silicon Valley to the arts city Cologne, networking eases the communication amongst a combination of actors in terms of cultural and educational exchanges, staff exchanges, co-operation between research centres (Landry et al., 1996; Simon, 1998). The power of networking enhances people's receptiveness, openmindedness and international orientation. It also is the driving engine of collaboration. Given sophisticated management, collaboration shortens the 'cognitive distance' between diverse players and stimulates more effective execution (Nooteboom, 2006). Moreover, Landry (2000) recognizes that networking capacity occurs between individuals or organizations, citywide and between cities. From his studies, it is observed that a comprehensive view of cities reveals a series of overlapping communities and networks that invisibly glue the region together by constantly generating multiple interactions while creating loyal connections - which each network sees the region in a different way from its own needs and perspective.

Similar to the reflection on networking capacity, a study conducted by Currid (2007) generates in-depth understanding of the social mechanism of how the arts and cultural economy operates in the New York City. Interested in exploring the agglomerations of talents that work in the 
creative industries - and more importantly, how sectoral advantages can be maximized for these people through the social mechanisms that are provided in particular places - Currid interviewed 80 participants in New York's artistic and cultural economy from 2004 to 2006 . Her findings indicate that social realm - the opportunities to obtain collective interaction - is of crucial importance to the creative workers as it not only provides access to sectoral acquaintances and gatekeepers, it also builds supportive communities for individual talents. The latter conclusion matches the work of Lloyd (2006) who conducted a study on Chicago's Bohemian neighbourhood, Wicker Park.

\subsection{Development of Related Terminologies}

While these justifications for the spatial concentration of talents and resources may be new, the defining efforts of such phenomenon can be traced back to the end of $20^{\text {th }}$ century. From a historical perspective, the act of forming creative or cultural quarters centered around public institutions and public spaces were pioneered as 'cultural industries strategies' during the 1980s in the UK as a response to the challenges of economic restructuring social and environmental decline as well as provide the basis for urban regeneration that will bring in investments in leisure facilities and intellectual jobs (Kahn et al., 2009). Moreover, Porter and Barber (2007) observe that these creative quarters are usually adopted in the interest of strengthening arts and cultural assets by utilizing the renovation of historical city centres so that their related creative industry production and consumption activities would reinforce the incubation roles of those places as cultivation of a milieu of creativity.

The concept of creative quarters is elaborated by Landry (2000) based on the explanation of certain spatial clustering of activities or concentration of creative ind ustries as an urban asset. He points out that such clustering of talent, skill and support infrastructures builds direct 
contribution to urban vitality and prosperity because its following achievements: mutual financial, technical and psychological support, efficiency of markets, the proximity of buys and sellers; as well as stimulating competition, generating multiplier effects, synergy complementary interchanges and swapping of resources. In Landry's view, that this spatial geography of creativity and clustering is generated from the convenience of trading, which further self-states the importance of human interaction - with face-to-face contacts has been and will continue to be a crucial aspect.

Besides creative/cultural quarters, the term convergence centres was identified by the "Strategies for Creative Cities Project (2006)" as one of the lessons learned in effectively addressing the needs of creative sectors which bears similar function in fostering networking and collaboration through enabling the co-location of diverse parties. Similar to the polycentric grid phenomenon in Europe in the late 1970s and 1980s where small individual small-scale artisans form polycentric grid zones for the ease of networking in order to ensure their competitiveness over large-scale manufacturers (eg. textiles, furniture, etc.) (Evans, 2009), it is recognized that the need for convergence centres originates from the need of linking and connecting creative practitioners, allowing them to learn from one and another, break down barriers between different scales of enterprise and organizations, which can uitimately stimulate urban creativity as subsequent economic gains. Convergence centres are home to creative spaces that welcome diversity and different scales of uses as well as "a flexible infrastructure that can respond to new ideas, opportunities, and developments" (p.12). Innovation centres, educational and public institutions such as universities and museums are examples of such kind.

Another similar definition which articulates a highly networked and non-hierarchical creativity concentration is the creative milieu. Amongst various scholars, Landry [2000] scrutinizes the 
origin, characteristics, and function of creative milieus. In his introduction, Landry writes (p.132);

Today the notion of necessary support services (for a creative milieu to flourish) has broadened from the presence of venture capitalists or distribution chains to embrace the need for cultural facilities, urban buzz often created by cultural industry entrepreneurs or arts types, social activities and more generally amenities linked to quality of life, including good housing, transport and health facilities. Urban milieu need to provide networking opportunities in non-work settings or between firms. This might include the capacity for a chance meeting in a café, a concert, a health club or school. What is important is discovering which types of urban environment encourage such interaction.

Under this ideology, Landry identifies a creative milieu as "a place - either a cluster of buildings, a part of a city, a city as a whole or a region - that contains the necessary preconditions in terms of 'hard' and 'soft' infrastructure to generate a flow of ideas and inventions" (p.133). He identifies that the built environment, both the stage and the setting, is crucial in establishing a creative milieu. Landry presents his idea around discovering and developing the city's hard and soft infrastructure as reassessing and visualizing hidden assets of precise economic value for wealth creation. Defined by Landry (2000), hard infrastructure is "the nexus of building and institutions such as research institutes, educational establishments, cultural facilities and other meeting places as well as support services such as transport, health and amenities". Meanwhile, soft infrastructure is "the system of associative structures and social networks, connections and human interactions that encourages the flow of ideas between individuals and institutes" (p.133). There exists a mutually interdependent relationship between hard and soft infrastructures - in which the former serves as the container for the value adding produced by 
the latter - the two together create a milieu in which the capacity of people connect, network, inter-relate and generate ideas that are turned into projects and services. Landry (2006) describes a creative milieu as containing "people and place together, a physical setting in which a critical mass of entrepreneurs, intellectuals, knowledge creators, administrators and power brokers can operate in an open-minded, collaborative context, and where face-to-face interaction creates new ideas, artifacts, products, services and institutions" (p.281).

Carta (2007) echoes upon Landry's idea on creative milieu and analyzes it as a local system within which "a critical mass of local councilors, entrepreneurs, intellectuals, social analysts, artists, promoters or student might operate, possessing the requisites for global interaction and where spatial intercourse creates new ideas, products, services and institutions, contributing to the city's regeneration and improved status" (p.15). Carta recognizes that the manifestation of a creative milieu should comprise a range of clusters or districts that are capable of strengthening the overall city cultural framework and that provide prerequisites for creative class to take root and foster a cultural-based renaissance. During the development of this theory, Carta (2007) proposes seven theoretical indices that outline the renewal characteristics of a creative milieu. They include: an identity index that displays profound cultural stratification of identity-related resources that function to reinforce area sense of belonging, together with the willingness and capacity of institutions to optimize such resources; an economic sustainability index to reflect on the existing economic base that is able to activate and maintain urban regeneration projects; a potentiality index that appraises the imbalance between different potential levels such as economic capacity, infrastructure supports etc. assessed by analysts, planners, artists, and entrepreneurs and sets it under the current circumstances and decision-making trends. They also include: a dynamism index that analyzes the competence and tools needed to produce and encourage future transformation of culture, science, and technology; an interaction index that 
allows a range of users and stakeholders to test out opportunities for informal and spontaneous forms of communication as well as the presence of suitable environments for diversity and variety; a multisector index that highlights the importance of a non-homogenous environment which considers various living accommodation, commercial businesses, and quality cultural activities; finally, a perturbation index that provides an indication of the latent energy which produces a disturbance and imbalance between the current situation and a vision for the future.

\subsection{Major Critiques: Displacement and Gentrification}

Focusing on pursuing frameworks what privilege the emergence of specialized cultural and creative districts, geographical concentration of creative industries and activities has a tendency of fragmenting the city or the region from being constantly recognized and developed. Having its well-defined boundaries, creative quarters could displace the clusters within the district from its broader urban context. Such phenomenon of "displacement", initially interpreted by Crang (1996), refers to an understanding of a place that is constituted through networks and representations which extend beyond the delimiting boundaries of a particular site. Today, under the popular 'creative city' agenda that inspires branding strategies for urban regions to adopt entrepreneurial models that attract investment (Hall and Hubbard, 1998; Peck, 2005), the particular focus on "place-making" can be easily translated into: construction of spectacular spaces of consumption, attractive streetscape, bohemian quarters, and flashy cultural infrastructures, etc. (Hannigan, 1999; Evans, 2003; Bell and Jayne, 2003; McNeill, 2007). Such fanatical commitment in producing creative and cultural quarters just for the sake of boosting urban economy results in the phenomenon that these districts are separated - or more precisely, displaced - from other areas in the city, suggesting that the 'creative city' strategies produce uneven urban geographies with only overall negative impacts on the creative industries (Peck, 
2005). As Gibson and Kong (2005) summarize, under such circumstance, creativity is valued only when it contributes positively to economic growth.

Correspondingly, gentrification is another outcome of lower-income residents being displaced from reinvestment practices that usually involve property conversions. Such gentrification is triggered by not only the creative sectors moving into the district themselves, but also by the upcoming influx of residents. Observed by Catungal et al. (2009), this kind of gentrification brought from economy-oriented district development differs from traditional patterns in that a wider array of actors are displaced - including not only working-class residents, but traditional manufacturing uses and members engaged in the creative industries.

\subsection{A 3Ps Framework for Defining Creative Hubs - people, place, and planning}

Following the changing urban economy throughout the past couple of decades, the concentrated geographic forms of the intraregional collaborative relationships need to be thoroughly recognized and analyzed. Justified by such milieu characteristics and economic benefits, as well as the positive outcomes generated from the process of development and implementation, this spatial concentration and clustering of people assets and infrastructure resources produces a phenomenon where urban creativity is more effectively fostered based on a hub-scale setting. Starting from where, the concept of creative hubs is established to characterize the emergence and maintenance of this phenomenon.

Creative hub can be firstly understood in its literal meaning: hubs that are creative. According to Webster Dictionary, a hub means "a centre of activity". It is where information most efficiently gathered and communicated. It is also where messages are interpreted, translated and synchronized to have central impact on how the region as a whole. Moreover, it is where 
brainstorming occurs and new ideas brew. Visually, hubs can be demonstrated by the following figure:

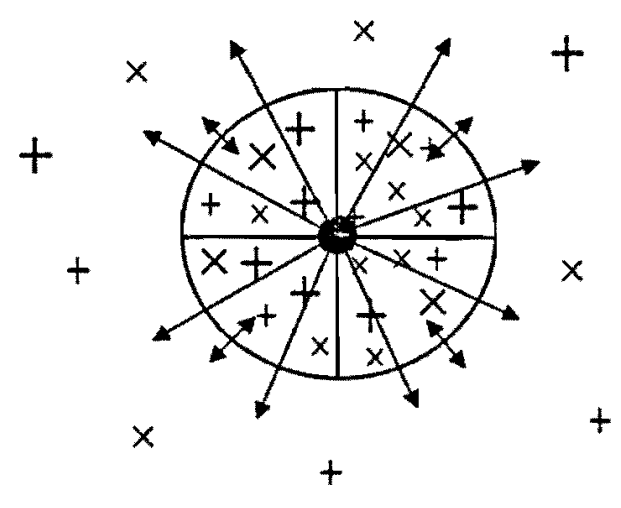

Prepared by Chen, 2010

In this figure, consider crosses of different angle represent interactions. With the large circle represents the imaginary boundary of a hub, it contains the area where most dense and rigorous interactions take place. The existence of those two-way arrows illustrates the prevalence of frequent information exchange - not only from inside of the hub, but also from the minor concentration spots outside the hub. In this sense, the concept of "hub" goes beyond "incubator" and "milieu", in a way that it emphasizes the dynamic communication flow in and out of the geographic boundary.

Based on the idea of urban creativity, the term "creative" focuses on the capacity of unleashing two types of potential to ultimately help modern cities adapt to today's culture-driven, technology-focused, and knowledge based economy. One type of potential concerns human creativity. The people elements play an important role in realizing and continuing the process of harnessing urban creativity. The other type of potential is discussed around utilizing and generating appropriate urban settings to satisfy the needs of human creativity. Infrastructure, 
planning tools, policies and regulations are considered as crucial implementation elements that enable the possibility of fostering creativity.

The following content scrutinizes the idea of a creative hub by asking three basic question.

\subsubsection{What function does a creative hub perform?}

Being a geographic concentration of innovation and social capital, a creative hub performs two major functions: a) It stimulates interaction occurring amongst heterogeneous and homogeneous groups (ie. the knowledge workers from both inter-and intra-creative industries/firms); b) It provides desirable amenities and infrastructures that help to facilitate diverse communications. While spatial proximity shortens the physical distance between different agents working in a creative hub, it also minimizes the communication obstacles between various groups. For both heterogeneous and homogeneous communities, a creative hub produces opportunities, with both soft amenities and hard infrastructures, for people to seek interaction based on their creative needs. Positioned in a pool of diversified talents and skilled professionals, a creative hub serves its users and agents with a highly encouraging and stimulating environment.

\subsubsection{What key elements mark a creative hub?}

A. People assets

As mentioned, talents is one of the fundamental elements for a creative hub. They are actors within different on-going information exchange processes. They are resources that form the well of inspiration, inventiveness, and innovation. While looking at a creative hub, it is important to describe the key characteristics of its people as a way to assess its capacity - industry breakdowns, business focuses, artistic appreciation, or even advocated concerns - depends on the nature of the creative hub. It is believed that 
the actors within a creative hub are decision makers who represent different interests based on their engagement in major institutions or organizations. They are assets to each other, as well as to the creative hub and the bigger region during the process where ideas are emerged and exchanged.

B. Knowledge relationships and social contacts

Resulting from the advantages of the prevailing interaction and collaboration, it is important that a creative hub is able to provide opportunities that generate knowledge relationships and social contacts that accelerate innovation. Spatial proximity is one of the specific advantages that effectively enables an innovation embedded collaboration process. Despite the various efficient communication means available in our modern society, the impact of face-to-face contacts is not diminished in a creative hub content because it has been observed in studies that it is the appropriate combination of knowledge relationships and social contacts between professionals from related industries that can provide preferential or even cost-free access to strategic information or services that promote sector development (Sweeney, 1987; Eisebith, 2004). Under such picture, the liveliness and vibrancy of a creative hub is fully manifested in a range of active information flows that work under massive knowledge relationships and social contacts.

C. Hub identity - image, vision and sense of belonging When a creative hub reaches certain levels of maturity as an economically successfully locality, actors from the inside would naturally form a coherent identity that has effects on the geographical area's image and vision (mostly for marketing), as well as a sense of belonging. Such identity determines the general boundaries of the hub not only for those performing within it but also those evaluating it from the outside. It fulfills the important 
function of harmonizing actors holding different professional backgrounds and interests and directing diverse groups towards common goals of locality development.

D. Quality of place

One of creative hub's key elements lies in a comprehensive sense of place for the hub defined by the neighbourhood, the human energy, and the vibrant street life.

Florida (2002) comments on quality of place as being more explicitly related to urban economic development and the behavior of a wide range of talents - for which he raises three key attributes: a) what's there - the buildings, the neighborhoods, the physical design; b) who's there - the people, the diversity, the human energy; and c) what's going on - the bustling street life, sidewalk cafes, restaurants and music venues, active outdoor recreation. More quality of place indicators are observed as amenities that provide access to natural, recreational lifestyle, as well as arts and entertainment - with basic elements including safety vibrancy, and other indefinable aspects such as authenticity, tolerance, street life, buzz, and urbanity (Donald and Morrow, 2003, Kloosterman and Trip, 2006; Glaeser et al, 2001; Gertler, 2004).

\subsubsection{What role does planning play during the course of establishing, developing and} maintaining a creative hub?

The nurturing of a creative hub requires incorporating planning as a set of comprehensive citymaking tools of building different tolerant, open, and encouraging environments that best accommodate interaction and innovation needs. Especially in today's urbanization context, the role of planning has been put in a particularly prioritized position to respond to a global economic transition that shifts the labour-intensive and industrial processing economy focus to a more culture-oriented and technology-based system of exploiting imagination and intellects. 
The emergence of creative hubs is a phenomenon of reassessing urban assets. Echoing the purpose of harnessing talents and skills, unleashing urban potential through establishing appropriate physical settings, planning provides both thinking and implementing frameworks to gather and exploiting urban resources to foster creativity. Concerning the geographic scope and function of creative hubs, it is planners' responsibilities to discover, recognize, manage and develop useable resources to understand an urban area's meaning of existence and organize different elements of a creative hub. Meanwhile, the changing paradigm of planning over the past couple of decades also signifies a transitional role that moves from the former top-down and centralized manner to a more inclusive system that engages a wider public and decision makers rather than those merely concerned with land use.

On the other hand, the culture dimension of leveraging urban assets is identified as significantly important in the planning process of a creative hub's emergence. It is mainly reflected from the historically strong focus of utilizing culture resources particularly during the establishing and reinforcing stage of a creative hub. As mentioned earlier, the idea of establishing "cultural quarters" was an early experiment as successful urban development strategies. Compared with today's emerging discussions on scientific and technological creativity, cultural resources and cultural planning were the creative industries back then and are continuing to be the raw and authentic inspirations for the shaping of any creative hubs. On one hand, cultural resources in an urban context include historical, artistic, and heritage representing assets such as old warehouses, post-war architecture, and urban landmarks. These tangible cultural inventories give an area its appearance of distinctiveness and uniqueness - which represents the primary statement of the rich cultural background of an area. On the other hand, related to those material cultural inventories in an area, it is recognized that certain traditions, attitudes, and habits are embodied and meanwhile being generated based on a sense of cultural identity. The 
scope of cultural elements in a defined community can be so strong and influential that planning strategies such as cultural mapping - to be elaborated in later sections - demonstrate overall powerfulness in reaching urban life aspects such as social cohesion, community pride, economic prosperity, and sustainability.

The following figure illustrates a general framework of three basic aspects to examine a creative hub. Having people assets, and quality places as the actual flesh and bones of a creative hub, it is the combination of both that builds up an incubator for creative industries and the area's dynamic flows of information exchanges. Reflected on different needs that circulated amongst diverse groups, the significance of planning for creativity is to come up with solutions to show the hub's initiatives in fulfilling those needs. Meanwhile, it provokes tools of providing accommodation and amenities for creativity by reinforcing the importance of maintaining quality places. When a healthy balancing point is reached between the three components of a creative hub, it is believed that the hub itself thus enters an optimal stage.

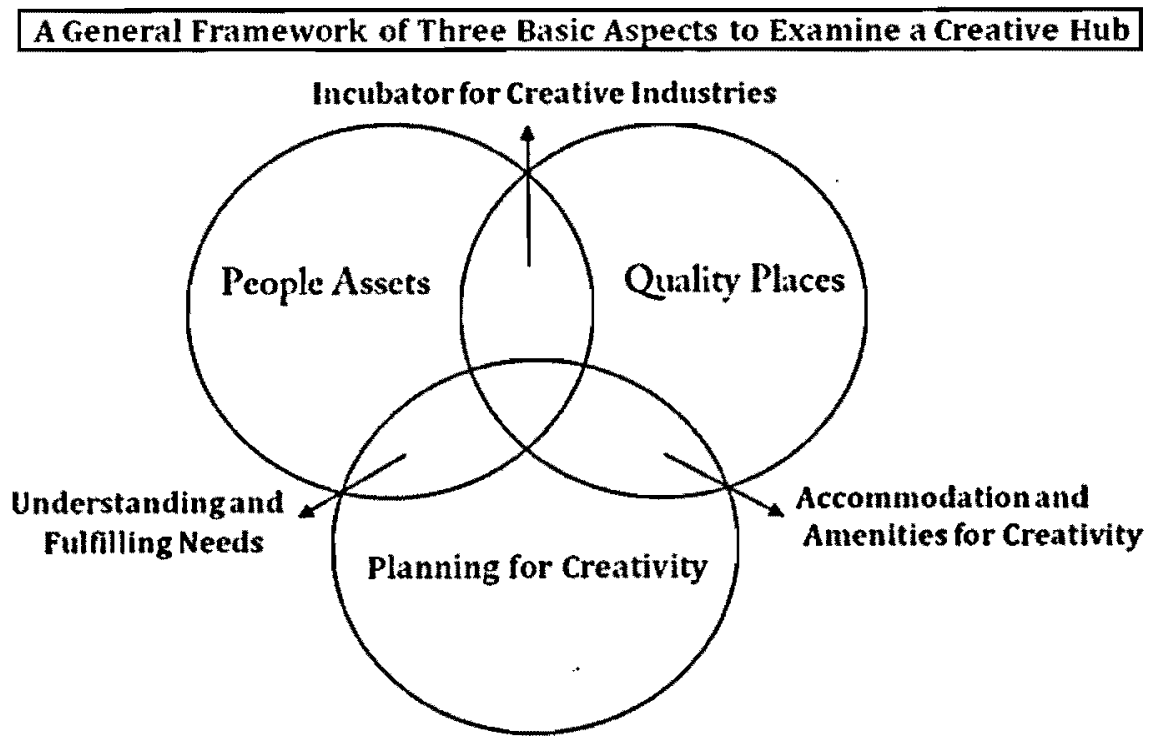

Prepared by Chen, 2010 


\section{CREATIVE-HUB DISTRIBUTION ANALYSIS IN TORONTO}

Positioned not only as the core of today's Canada's knowledge and innovation-driven economy, but also as a world city that serves global-level markets with rich social, cultural, and economic diversity, Toronto recognizes its immense competitive advantage and strives for growing prosperity by placing creativity on its long-term agenda. Imagine a Toronto (2006) concluded that, "There is a direct link between a flourishing city and the vitality of its creative sector. Toronto is on the cusp of a creative breakthrough." In 2007, Mayor David Miller envisioned creativity as an economic engine for the City of Toronto by stating, "We must put creativity at the heart of Toronto's economic development strategy"1.

On a par with famous international urban centres such as New York, London, SanFrancisco, Paris, Toronto has what it takes to enter the next level of becoming a global creative city. It has been ranked No.1 city in North America for Best Quality of Life and Top City Region of the Future by FDI (Foreign Direct Investment) Magazine, and No.2 in North America in the 2007 Mercer Human Resources Quality of Life Survey. Home to over 100 spoken languages and dialects, Toronto is one of the most diverse cities in the world with half of its residents born outside of Canada. Being the third largest biotechnology centre in North America, Toronto has the biggest biomedical research sector in this continent. Behind New York and Chicago, Toronto is the third largest financial centre in North America. Being the third largest centre for screen-based arts, film and television production in North America, Toronto is the third largest English-language theatre market in the world. Toronto is also the second fastest growing major employment region in North America and contains $80 \%$ of Canada's largest Research \& Development, law, advertising and high-tech firms. Moreover, having the third largest design workforce in North

\footnotetext{
${ }^{1}$ Quoted in David Miller (2007) "What makes a city great? Toronto 2010: Mayor David Miller's vision of a great city". Found at http:/wwwitoronto.ca/mavor miller/odf/miller platform webed screen.pdf
} 
America, Toronto has been ranked the highest among Canadian cities for patents, $17^{\text {th }}$ in the world. Generating an annual GDP of more than $\$ 9$ billion, Toronto is the base for $90 \%$ of Ontario's creative industries. (Agenda for Prosperity Report, 2008)

Recognizing its unique assets for nurturing creativity, Toronto has already identified in some studies the phenomenon of how creative workers and industries concentrate as thriving economic nodes within the city. Therefore, this section will examine how such phenomenon is discussed and suggested, followed by introducing a creative-hub framework for Toronto.

In 2006, Toronto was one of six urban case studies undertaken for the Strategies for Creative Cities Project (the other five being New York, London, San Francisco, Barcelona, and Berlin). In its summary report Imagine a Toronto, references are made from the Creative London's Hub Strategy which proposes several titles to describe the role of creative hubs - incubators for creative businesses, clearinghouse of information on locally available property, developers of long-term plans for the local creative sector and promoters of local creative work. Influenced by how Graham Hitchen, London Development Agency's Head of Creative Industries, describes Creative Hubs as 'areas where we think there is potential to really consolidate a cluster of activity that might have started to emerge and then dramatically growing that local economy through the creative business sector', the report proposes the idea of "creative community hubs" being transformed from local community centres as a way to leverage local resources. It is suggested that by undertaking economic revitalization and development programs in at-risk neighbourhoods, appropriate financial support can capitalize on local organizations and make use of their local knowledge to design adaptive approaches in attracting creative talents. In the case of Toronto, neighbourhoods with such strong potential for nurturing grassroots creativity such as the Queen Street West. 
In 2008, a report named Agenda for Prosperity which is prepared by Toronto Mayor's Economic Competitiveness Advisory Committee came out. In the content of the report and its supporting document Creative City Planning Framework, produced by AuthentiCity - a Toronto-based consulting firm that specializes in cultural planning and creative sector development, the term "creative hub" is used in a more frequent and determined way compared with any previous study. In Agenda for Prosperity, while Toronto is considered as a creative hub itself - as well as a hub for innovation, for transportation, etc. - in the general Canadian city context, suggestions are being proposed as to "establish creative hubs and districts as geographical concentrations of interconnected individuals, organizations and institutions involved in the arts, cultural industries, new media, design, knowledge building and/or other creative sector pursuits" (p.26). Later in Creative City Planning Framework, the creativity concept is more thoroughly defined as the most inner sphere model of creativity - outer ones include creative \& cultural industries, creative economy, and creative city. It is stated in this report that creative hubs are manifested in specific buildings and districts - that they are generated from groupings of interconnected and interdependent businesses, institutions, places, and scientific and cultural resources. Moreover, the report observes that creative hubs either form spontaneously or can be formally developed as convergence centres to accommodate the acceleration of research. Institutions and built structure such as MaRS, the Art Gallery of Ontario, the Royal museum of Ontario, or districts such as the Gooderham and Worts Distillery, etc. are all examples of such creative hubs.

The year 2009 saw several major studies and conferences took place in Toronto. They rigorously echoed the idea of nurturing urban creativity and how it is reflected and practiced both on a city and a regional level.

During early 2009, Toronto Artscape - a non-profit development organization initiated by the Toronto Arts Council involving in creative community building - presented its research results 
of the project Vision 2011: Thinking Big about Culture-led Regeneration. The study mainly focuses on the culture-led regeneration projects done by Artscape with three central themes: leadership, spacemaking, and placemaking. Creativity is generally articulated in relation to the latter two planning initiatives. Focusing on a rather geographical perspective, creative hub is defined as "a multi-tenant centre, complex or place-based network that functions as a focal point of cultural activity and/or creative entrepreneurship incubation within a community. It provides an innovative platform for combining the necessary hard and soft infrastructure to support the space and programming needs of commercial, not-for-profit and community sectors." (p.22).

From June $9^{\text {th }}$ to $1^{\text {th }}$, the first Placing Creativity conference was held in Martin Prosperity Institute in MaRS Centre. In conjunction with the Creative City Planning Framework documents, this conference was largely sponsored by the City of Toronto and the Ontario Ministry of Culture. A large number of practical and intellectual thinkers gathered to discuss the art and science of mapping creativity in urban centres. As the conference name implied, the goal of Placing Creativity is to stimulate discussions about place and creativity, and to develop creative ways of leveraging connections between culture, economy and places. The "mapping" brainstorming is one of the key themes of the conference and it is also a continuation of the cultural mapping discussion in the Creative City Planning Framework documents. Focusing on a place-based approach in mapping cultural assets, urban resources, and creative industries, different speakers at the conference emphasized the importance of how such mapping systems can more effectively reallocate the corresponding place elements and facilitating infrastructure to finally stimulate creative cluster activity and economic growth.

In order to further elaborate this mapping concept, in relation with the creative hub phenomenon proposed in this paper, I interviewed Dr. Greg Baeker, a senior consultant, also the 
Principal of AuthentiCity. He is co-author of the Creative City Planning Framework, as well he was a guest speaker at the Placing Creativity conference. Baeker points out that the notion of mapping creative clusters can be observed at two levels. One is a hub-level that is generated from physical proximity of creative industries. The other is a sector-level that focuses on the connectivity of creative industries. When exploring the hub-level creativity concentration phenomenon, as he suggests, not only is it important to specify the types of businesses and industries that congregate as creative activities, but also to relate the planning, economic, and cultural spheres together to examine interconnections within and among hubs.

First, the planning context should be studied in terms of traditional planning interventions such as zoning, and creative planning as community development tools. Here the necessity of building hard and soft infrastructures is brought up in understanding planning as not only interventional methods that shape continuous material characteristics, but also as a social media way to support the intangible framework that enables people in the community or among communities to connect.

Second, economic traction is a leading factor that encourages the formation of geographic creative clusters. Baeker suggests that different scales for certain types of industries congregate spatially that in turn help to define creative hubs. For instance, a purposely built facility can provide strong enough economic attraction for certain industries to concentrate. Termed as "convergence centre", it usually represents incubator centre on a much smaller scale - around which hubs are emerged in expanding the creativity ecologies.

Finally, cultural mapping is a significant aspect in building creative hubs. Emphasized in a number of Baeker's publications and speeches, the process of mapping cultural resources and urban assets is a tool for identifying creative ecologies - geographic relationships of the distribution of creative assets such as human resources, quality built environment and creative institutions. 
Shortly after the Placing Creativity conference, The Convergence Centres - Building Capacity for Innovation was published in July 2009. It is the final report of Artscape's Creative Convergence Project initiated in 2007 by a consortium of leading institutions, non-profit enterprises, private sector organizations and government agencies partnered to develop and promote a place-based approach to creative sector development in the Toronto region. As multi-dimensional and designed with explicit intent to build capacity for creativity and innovation, convergence centres "leverage investment at the intersection of place, culture, technology and entrepreneurship to generate multiple dividends of economic and social value" (p. 5). The project mainly identifies three significant 'macro' challenges shared across Toronto's cultural and creative sectors. They are: 1) Talent, which is the challenge of cultivating entrepreneurial capacity, business skills and workforce development. 2) Space/Place, which is the challenged of sustaining and developing infrastructure and urban environments that stimulate creativity and innovation. 3) Collaboration, which is the challenge of connecting creative people and assets. The report suggests that by unlocking these three types of potential, Toronto's portfolio of 'convergence centres' reflects "a new generation of institutions in the region that collectively provide a model for addressing these overarching challenges for the sector" (p.15).

On one hand, based on the literature review, we can observe that Toronto's unique assets of cultural infrastructure and diverse assets determine its role as a creative hub of the Ontario Province and Canada - in a way that the city demonstrates a rather solid combination of the three basic components of people assets, quality places, and planning for creativity. On the other hand, previously cited research projects help to lay out the foundation of exploring the creative-hub distribution in the City of Toronto. It is observed that, a range of smaller-scale creative hubs within Toronto comprises a more complex and important creative-hub framework that can be categorized at two levels: institutional level and district level - usually with the 
former existing as creative nodes located within the larger geographic area of the latter. Institutional level creative hubs include research and convergence centres such as MaRS and University of Toronto; creative enterprise spaces such as 401 Richmond; social innovation centres such as the Robertson Building at 215 Spadina; and arts and cultural facilities such as the Canadian Opera Company, the Art Gallery of Ontario, the National Ballet School, and the Royal Ontario Museum. They serve as the resource-stations for their district-level creative hubs providing appropriate, efficient, and optimal information channels for different fields of professionals and talents to interact and communicate. Compared with district-level creative hubs, institutional-level creative hubs are more people-based and simple-structure entities. Their visions are more directly articulated and easily comprehended, the information exchanges within those institutional-level creative hubs are also more reciprocal and goal-oriented. The district-level creative hubs, on the other hand, are more complex and more frequently involved with creative planning.

Building on the discussion, this study takes up a mapping system in order to provide a preliminary assessment of the creative-hub distribution in the City of Toronto.

In the latest cultural planning project - Putting Arts and Culture on the Map: Literally! (2010) conducted by Hill Strategies Research Inc., the research team visualizes the distribution of cultural talents by mapping their concentration (in terms of places of work) in the categories of artists $^{2}$ and cultural workers ${ }^{3}$.

\footnotetext{
${ }^{2}$ Arts occupation include: visual arts and crafts (painters, sculptors and other visual artists; artisans and craftspersons); writing; performing arts and film (actors and comedians; conductors, composers and arrangers; dancers; musicians and singers; producers, directors, choreographers and related occupations)

${ }^{3}$ Cultural occupations include: Creative, production, technical and management occupations in broadcasting film and video sound recording performing arts publishing, printing libraries archives, heritage architecture and design
} 


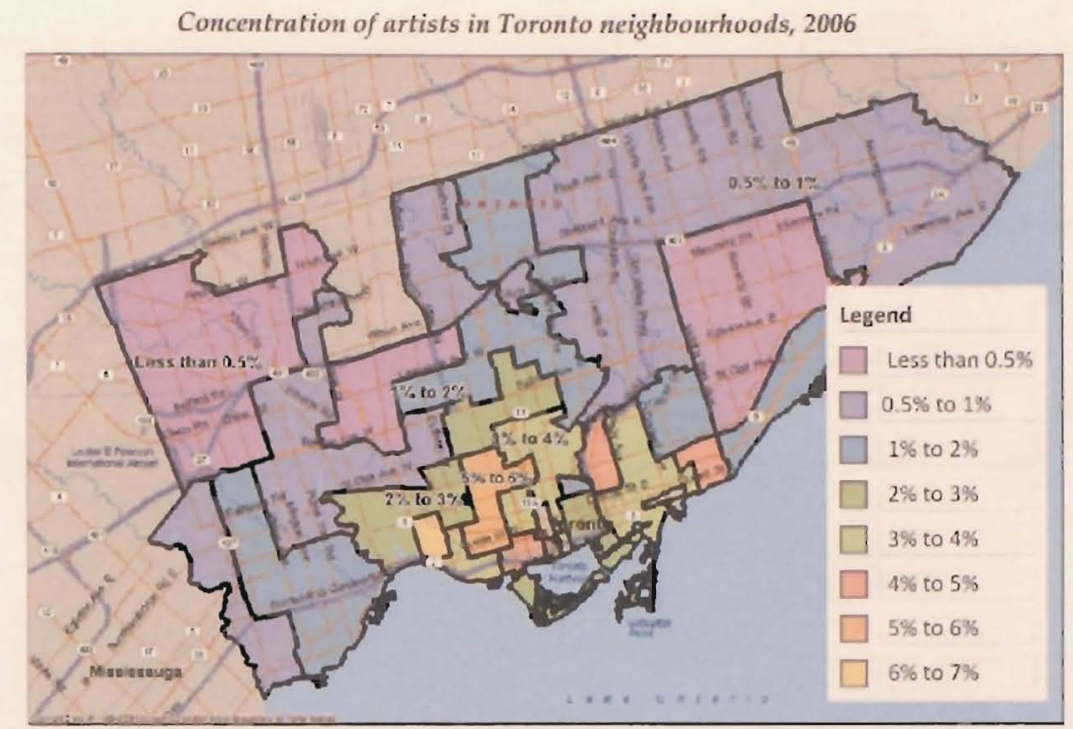

Source: Analysis by Hill Strategies Research based on a 2006 census custom data request.

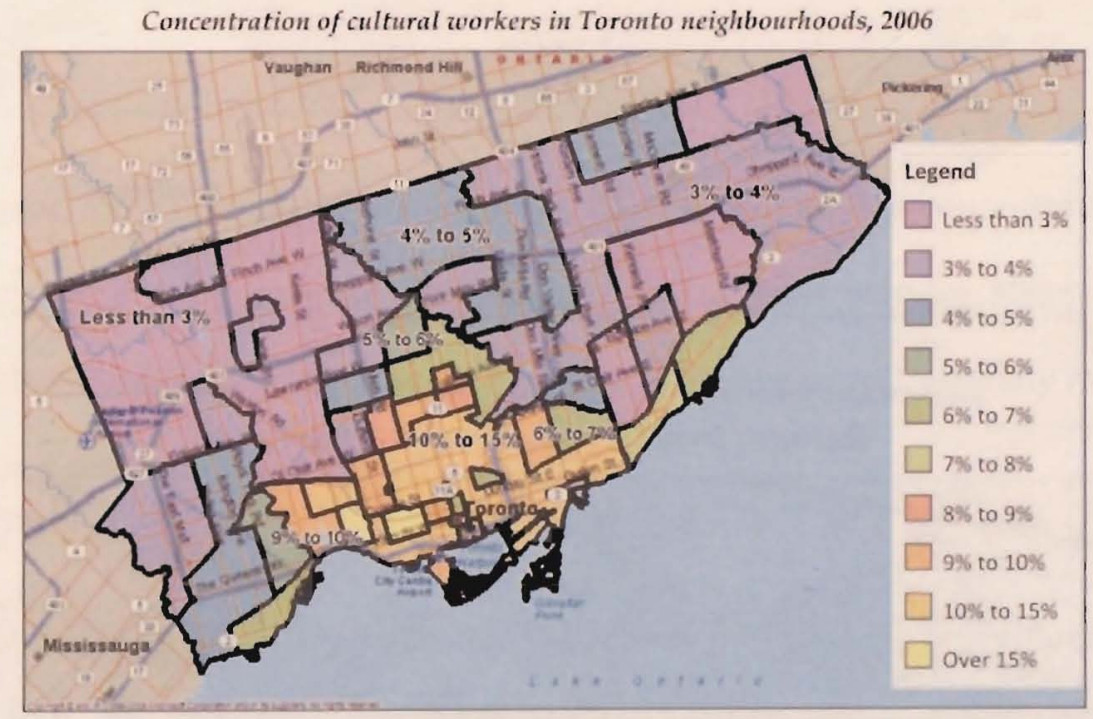

Source: Analysis by Hill Strategies Research based on a 2006 census custom data request.

Based on the figures above, it can be concluded that the current arts and cultural workers clearly tend to concentrate in the downtown area. Compared with cultural workers, artists show a stronger sign of developing in the downtown core in smaller community chunks.

In 2009, Convergence Centre Project conducted by Artscape Toronto using the same definition for creative sector developed by Work Foundation and National Endowment for Science, 
Technology and Arts (NESTA) in the UK to develop a graphical representation of creative sector in terms of establishment location, sizes and types of industries, and location quotient distribution (see figures below).

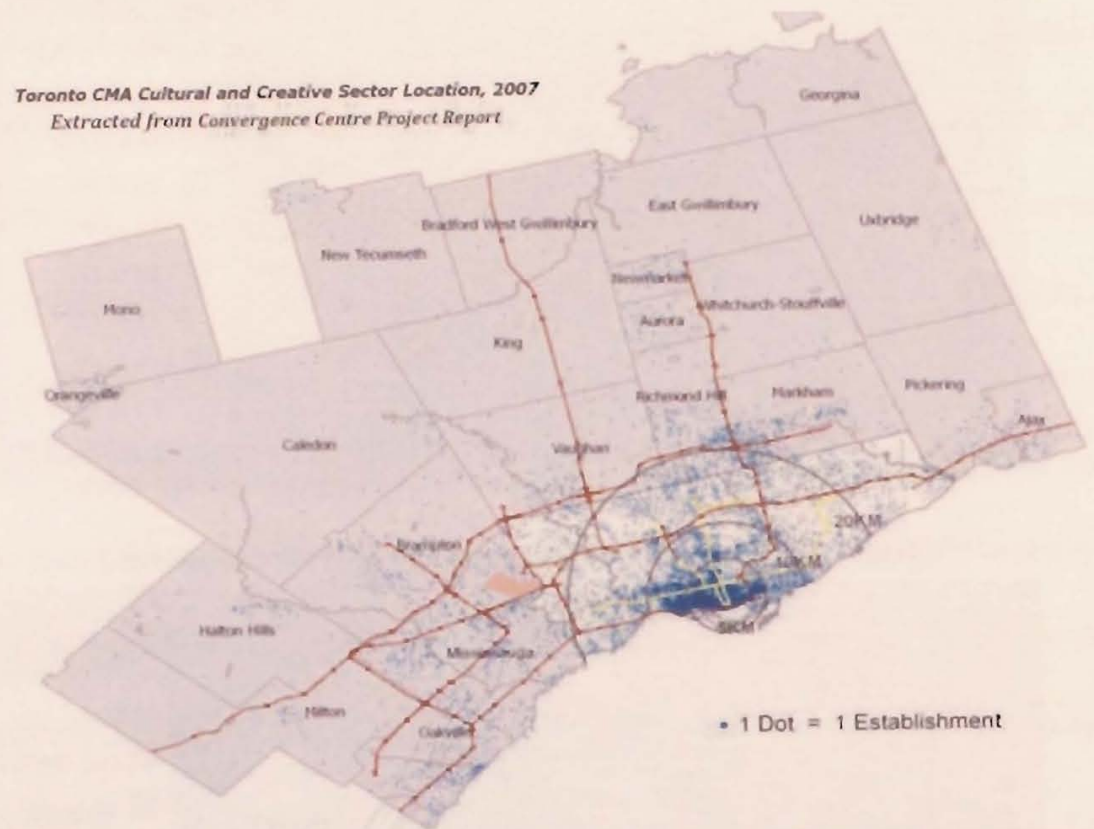

Source: 2007 Dunn \& Bradstreet Business Data, Toronto Arts Councl Grant Database, City of Toronto Cultural Facilities Database

Cultural and Creative Sector Location and Employment Size, 2007

Extracted from Convergence Centre Project Report

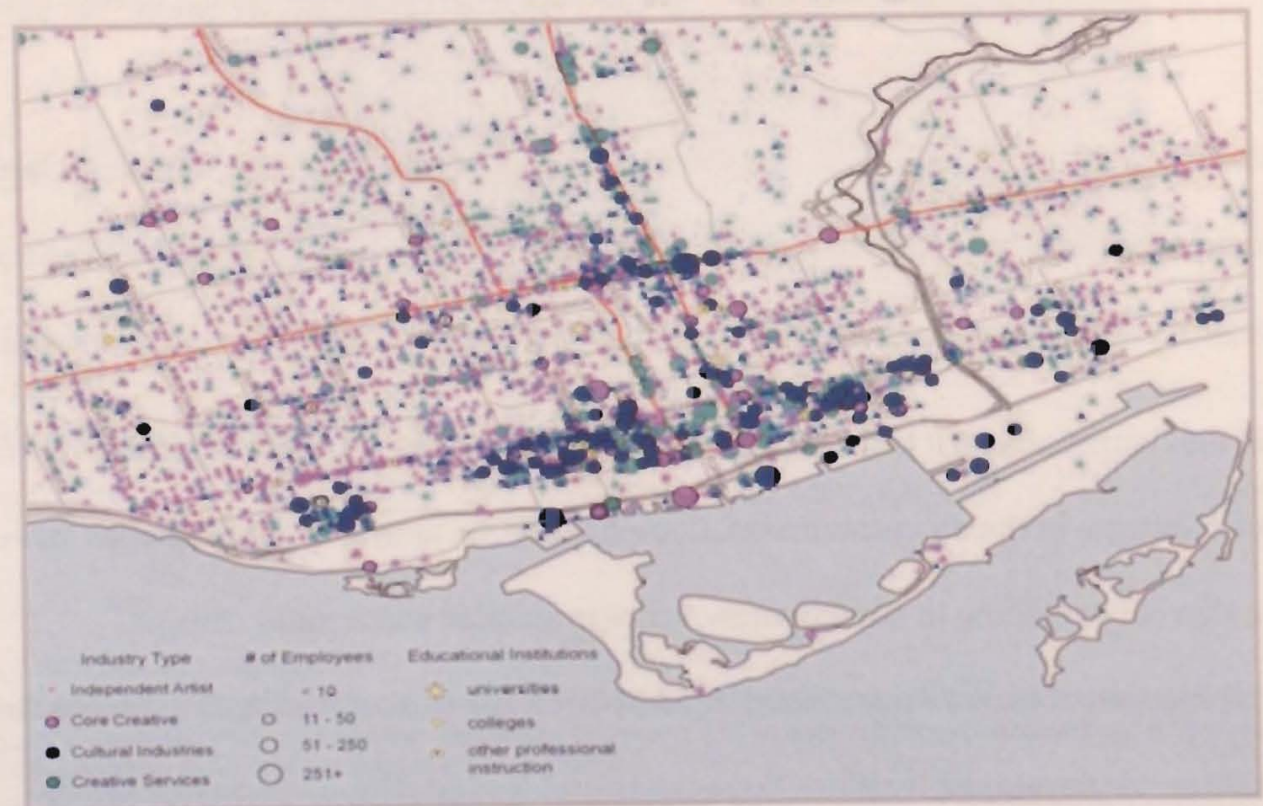

Source: 2007 Dunn of Bradstreet Business Dats, Toronto Arts Council Grant Databuse, City of Toronto Cultural Facilies Database 


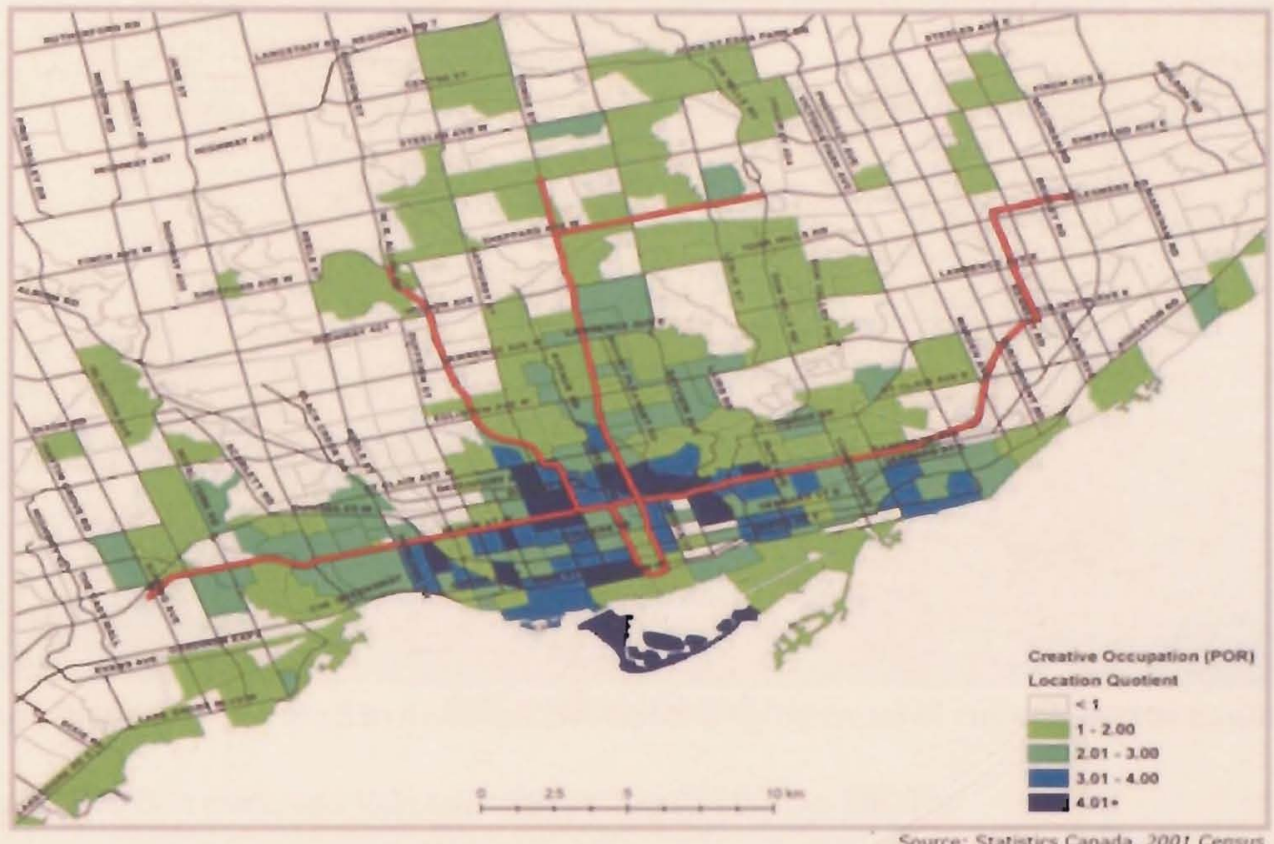

From these maps, it can be detected that the City of Toronto has a dense concentration of creative actvity in the south downtown core mostly on a East-west corridor. Meanwhile, creative establishments and institutions are observed spreading along University Avenue and Yonge Street in a north-south direction.

Relating back to the representative innovation nodes in the city that are generally considered as creative hubs, this paper thus examines the creative-hub distribution for Toronto that can be demonstrated further through a mapping lens. In the following figure, the creative hub distribution in Toronto follows two directions: East-west district-level congregation (highlighted in pink), and the north-south institutional-level congregation (highlighted in yellow). 


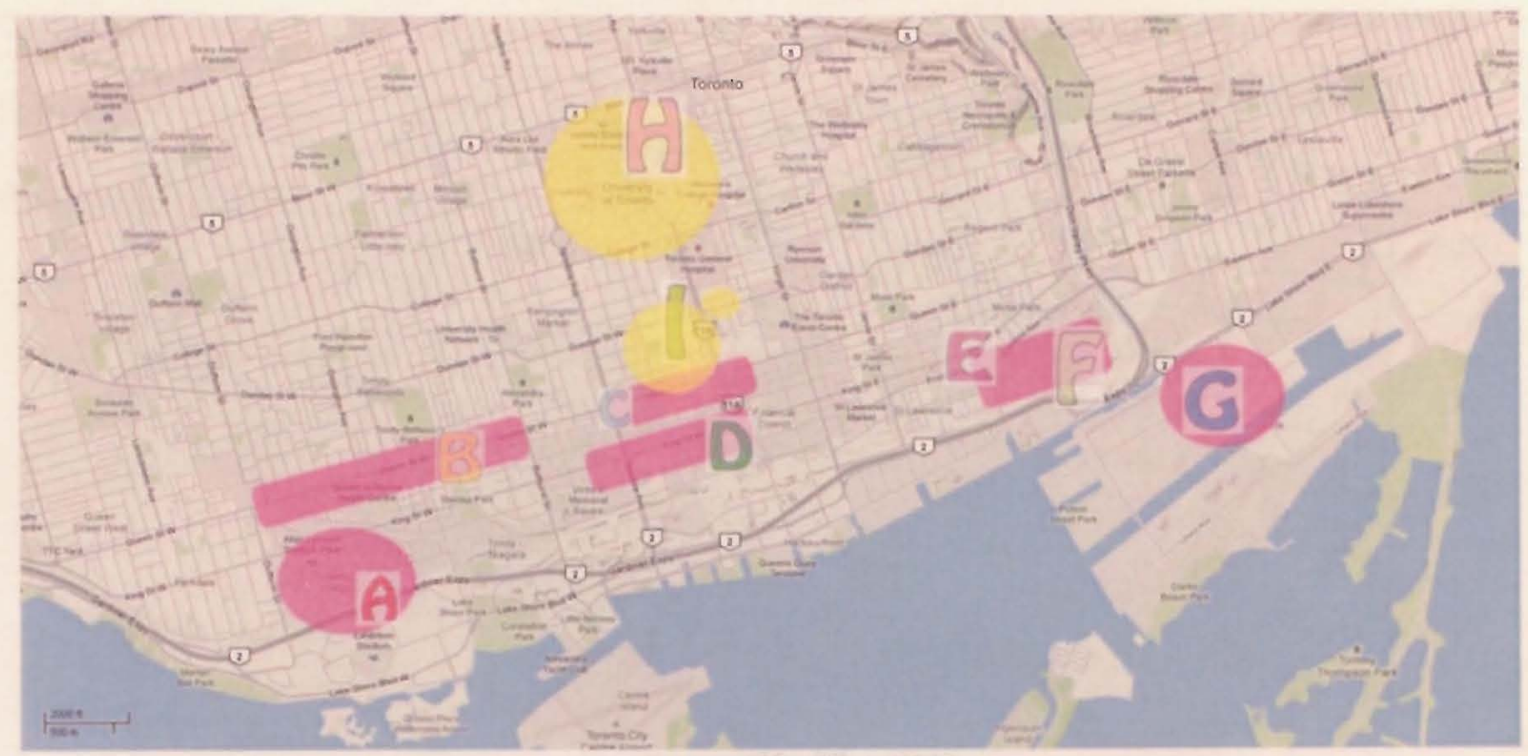

Prepared by Chen, 2010

First, for the ease of boundary definition, creative hubs are identified by specific street borders (as shown by the alphabetic in the map).

The East-west district-level congregation include:

A. Liberty Village (bordered by Dufferin Street, King Street West, Strachan Avenue, Gardiner Expressway);

B. West Queen West (bordered by Gladstone Avenue, Queen Street West, Bathurst Street, Canadian National Railway);

C. Fashion District (bordered by Bathurst Street, Queen Street West, University Avenue, Adelaide Street West);

D. Entertainment District (bordered by Portland Street, Adelaide Street West, Simcoe Street, King Street West);

E. King-Parliament Area (bordered by Sherbourne Street, Adelaide Street East, Cherry Street, Gardiner Expressway); 
F. Distillery District (bordered by Parliament Street, Mill Street, Cherry Street, Gardiner Expressway];

G. Pinewood Toronto Studios, Filmport (bordered by Don Roadway, Lakeshore Blvd, Carlaw Avenue, Shipping Channel].

The north-south institutional-level congregation include:

H. University District (bordered by St. George Street, Bloor Street, Bay Street College Street);

I. Arts and Cultural District (bordered by Beverly Street, Dundas Street West, University Avenue, Queen Street West];

The graph below is generated to demonstrate the emerging trend of cultural sector employment in each district. It is observed that over the period of 2006 to $2008^{4}$ :

- All the districts have a rather high percentage of cultural sector employment compared with the city levels.

- Although there has been no dramatic fluctuation, the employment engagement in the cultural sector in all districts experienced stable increases in 2008 compare with 2006.

${ }^{4}$ Toronto Employment Survey, 2006, 2007, 2008

${ }^{5}$ Census Canada shows that the cultural sector employment percentage for the Toronto CMA is only $3.9 \%$ in the year 2006. 


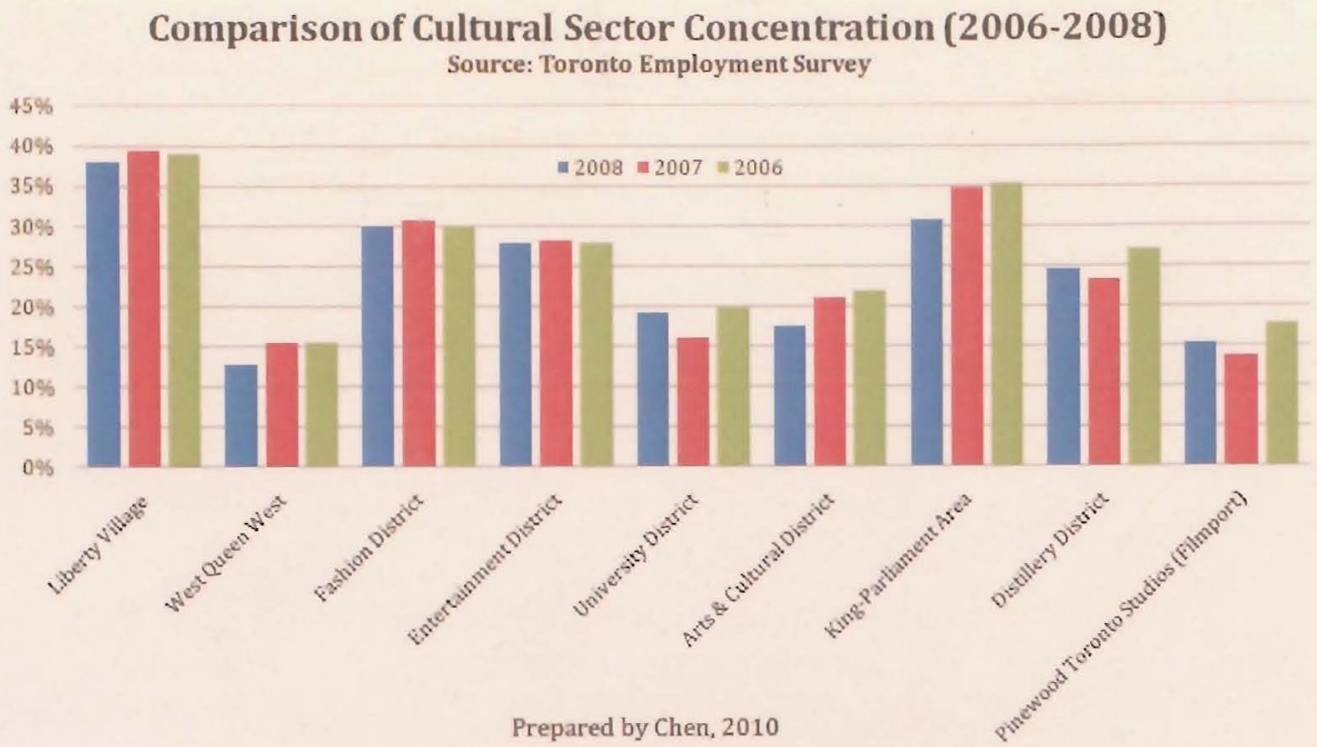

In order to further understand the phenomenon of how these creative hubs scatter in Toronto's downtown core following the previously mentioned directions, the following sections provide a qualitative analysis of such creative-hub distribution.

\subsection{North-South Direction and Institutional-level Creative hubs Congregation}

North from Bloor Street, to South at Front Street, the areas around University Avenue and Yonge Street contain concentrations of institutional-level creative hubs in the form of educational institutions (such as University of Toronto, Ryerson University, and Ontario College of Arts and Design), major arts and cultural facilities (such as Royal Ontario Museum and Art Gallery of Ontario), and innovative convergence centres (such as MaRS).

The Cultural Renaissance investment was pledged by the federal and provincial governments with an investment of $\$ 233$ million made to Toronto in May 2002. A series of cultural renewal and urban regeneration projects have been launched including rebuilding seven major cultural 
institutions that extend along University Avenue as a "boulevard of creativity"6. Royal Ontario Museum, the Royal Conservatory of Music, the Gardiner Museum, the Art Gallery of Ontario, Roy Thomson Hall, the new Opera House and the Toronto International Film Festival - as the seven ambitious projects - are marketed as a cultural entity that have been considered as the most prosperous and vibrant cultural corridor in the City of Toronto. This type of concentration itself represents the phenomenon of small-scale creative hubs formation as areas spreading from specific creative institutions.

On the other hand, specific institutional-level creative hubs can be powerful enough to drive substantial creative interaction given certain amount of working talents and networking capacities. MaRS is a good example. As a non-profit innovation centre aiming at connecting science, technology, and social entrepreneurs in order to facilitate and accelerate the growth of Canadian enterprises, MaRS Centre is home to the top researchers, entrepreneurs, and scientists in the country. In terms of networking capacities, MaRS Centre is not only engaged in partnerships with significant regional (such as the innovation institutions and research alliances in the Greater Toronto Area) and national organizations (such as Canada's Venture Capital and Private Equity Association and Information Technology Association of Canada), it is also connected to a broad range of research and innovation networks (such as Social innovation Generation (SiG) and University of Waterloo].

\subsection{East-west Direction and District-level Creative hubs Congregation}

From the Liberty Village and West Queen West on the west end, to the Fashion District and Entertainment District in the middle of south downtown core, and to the Distillery District and the Pinewood Toronto Film Studios (the Filmport) on the east end, the long corridor running between Queen Street and King Street contains the vibrant and lively neighbourhoods that

\footnotetext{
${ }^{6}$ As phrased in the Culture Plan for the Creative City, Toronto (2003)
} 
provide quality environments and mobilizing communication networks. This attracts an influx of talent arriving to seek opportunities that will help people to realize their creative potential.

These geographic clusters are creative hubs because of their distinctive capacities produce and commercialize expressive and functional values through maintaining their people assets, quality places, as well as an open and creative planning environment. That said, while their dimensions of performing as creative hubs may appear similar, they each holds different tractors and characters as a district-level creative hub.

West Queen West District, spreading from Gladstone Avenue to Bathurst Street along Queen Street West, is home to Canada's biggest concentration of fine art galleries, artist collectives and museums ${ }^{7}$. Its thriving artistic ethos and diverse working spaces keeps attracting arts and design workers to gather around. With proper heritage preservation and encouragement of continuous retail environment from the City, the West Queen West District is now another fast growing entertainment and cultural urban strip where the hip workers love to meet and socialize.

Compared with West Queen West, the Entertainment District roughly bounded by Portland Street, Adelaide Street West, Simcoe Street, and King Street West earns its reputation a bit earlier and is more well-known for its entertainment function as a hub where creative workers make use of its leisure facilities such as theatres, old-fashioned restaurants, and nightclubs.

Nearby is the location of Fashion District - running through Queen Street West between Bathurst Street and University Avenue. As a creative hub, it is home to the City's most number of fashion-related businesses.

7 West Queen West BIA: http://westqueenwestca/ 
The east-end precinct of this corridor contains two major creative hubs: the Distillery District and the Pinewood Toronto Film Studios. The former being a national historic site, has been redeveloped as a pedestrian-only village that is mainly dedicated to arts, culture, and entertainment. Holding a rich cultural inventory consists of galleries, restaurants, cafes, and performing arts spaces, the Distillery is the City's important creative production hub. On its website, it is shown that the district accommodates a diverse mix of enterprises including interior design (eg. Corktown); theatre (eg. Soulpepper Theatre Company); advertising (eg. Dream It); galleries (eg. Sandra Ainsley); artist/designer-maker (eg. Dish Gallery + Studio); education (eg. George Brown Theatre School); interactive media (eg. Groove Games); film/tv post production (eg. Distillery Post); and publishing (eg. SPORT Classic Books).

Meanwhile, located just a bit east to the Distillery District, the Pinewood Toronto Film Studios formerly known as the Filmport and Canada's Largest Film \& Television Production Complex visions to be more than a film production facility. It is currently becoming a convergence district for creative industries by developing infrastructure of recreation, culture and tourist amenities ${ }^{9}$. Also, its proximity to the Beach, Riverdale, and the Toronto Islands is gradually linking these potential creative areas into a larger creative triangle located at the east end of downtown Toronto.

From a planning perspective, the congregation of the East-west direction, district-level creative hubs can be better understood considering several key regeneration initiatives' taking place in the geographical areas - particularly in the two Kings (the King-Parliament and the KingSpadina) as well as their adjacent districts. In late 1995, Toronto's City Council adopted a

${ }^{8}$ See: htto://www.thedistillerydistrict.com/framesethtml

- See: http://wwwrosecorp,com/pdfs/filmport brochure.pdf 
planning report, New Directions for Physical Planning: The Three Lenses, that recognized a brand new approach that let physical design lead the regeneration process in certain areas. The three lenses are: 1) areas designated for major reinvestment and development such as the downtown, waterfront, brownfields and greenfields, which will have new tools available such as tax increment financing as incentives; 2) established, relatively stable areas where major change is not desirable such as many of Toronto's neighbourhoods, which will have policies to protect their character yet improve amenities; and 3) areas where gradual change is both expected and desirable such as along the major arterials of the city, which need to have clear visions for their incremental development to enhance their qualities through reurbanization (Toronto, 1995: 2736). Accordingly, the designation of reinvestment areas - that later became regeneration areas largely helped to encourage the design-led planning initiatives occurring in the district to construct an attractive and healthy environment for the influx of creative activities. Based on more tolerant zoning regulations, the reinvestment areas are able to establish built forms that giving the neigh bourhood the desirable character. Just as what Jacobs (1961) and Lynch (1960) indicate as examples, built form such as sidewalks, building scale and density, and mix of land uses can greatly influence how space users experience and use a place. It is the uses of those physical elements that in turn construct, articulate, and reproduce what the place is. Moreover, physical design of place-building tends to leave immediate visible traces. Paulsen (2004) emphasizes that the work of architects, planners, and landscape builders not only creates physical structures, but also directs action on the ground in a way that such action would largely influence direct human activities. 


\section{A CREATIVE HUB CASE STUDY - LIBERTY VILLAGE}

This Liberty Village case study focuses on one of the west-end creative hubs with an emergence experience similar to other district-level creative hubs in Toronto such as the Distillery and the King-Spadina Entertainment area. Through examining its three components: people assets, quality places, and planning initiatives, the case study aims to present a general picture of how different factors mark the significance and functional character of a district-level creative hub.

\section{Liberty Village}

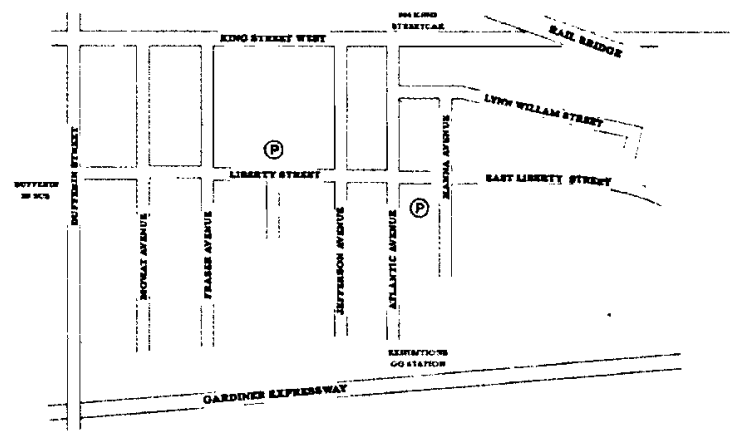

Source: The Liberty Village BIA

Located on the western edge of downtown Toronto, Liberty Village is bound by King Street West, Dufferin Street, Strachan Avenue, and the Gardiner Expressway. Used as a military fortification for the Town of York, this area later experienced an extensive warehouse and factory construction. In the 1850s, Liberty Village has been a prosperous industrial site because of its access to the downtown lines of the Canadian Pacific and Grand Trunk (now Canadian National) Railway lines. From late 1800 s to mid 1900 s, the Liberty Village area saw two major prisons closed down, big industrial factories going into businesses, and large-scale manufacturing companies entering this side of the city seeking opportunities. Given this historic background, the emergence of Liberty Village as today's creative hub for creative industries was triggered by its long existing attractive location for enterprises and legacy of 'brick-and-beam' architecture 
that redefined its role as an creative employment district since the economic transformation in the form of markets liberalization and the corresponding competitive pressures on local manufacturing business starting from the 1970s (Liberty Village Area Study, 2006).

Today, Liberty Village has turned into a 39-acre master-planned community combined with residential, commercial and retail uses - home to approximately 500 businesses - the majority being high-tech and creative firms, and 7500 full time and part time employees ${ }^{10}$. In the Liberty Village Area Study conducted by the City of Toronto in 2006 , it is commented that not only is the area one of Toronto's fastest growing employment districts, Liberty Village is now transforming into a "creative class" employment centre that is "built on the significant number of historic industrial buildings, providing a distinct character" (p.2).

\subsection{People Assets}

The figure below demonstrates the establishments breakdown of the Liberty village's employment. With Media being the top employment industry (taking up more than $20 \%$ ) in the district, Business Services and Food are the other two prominent employers.

\footnotetext{
${ }^{10}$ See http://www.IVbia.com
} 


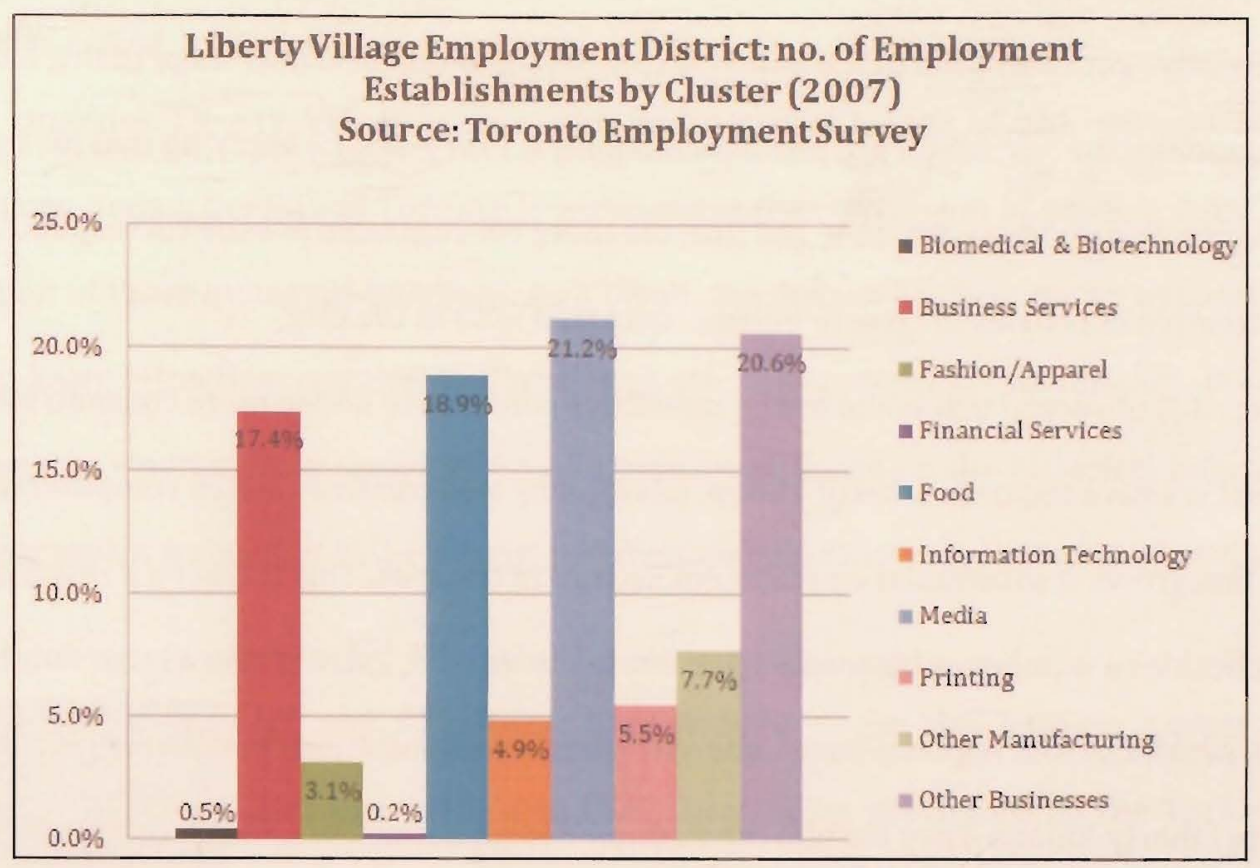

Figure 1 in the Appendix elaborates on the type of business and firm information for the top 20 companies located in Liberty Village. It shows that well-known media entities such as Corus Entertainment (YTV) and Nelvana (international producers and distributors of children's animation and related consumer products) employ the majority of the creative workers in the district. Besides media, high-tech firms such as Softchoice and Tucows Inc. are also listed as key employers in Liberty Village.

In order to illustrate the industry dynamics in the area, the Toronto Employment Survey used a special tabulation method that shows size comparisons of creative sectors and their compound annual growth over a 10-year period in Liberty Village. In the following figure, three key dimensions are demonstrated in a Growth-Share Matrix:

- Total employment of the industry(bubble size)

- Compound annual growth of the employment from 1997-2007 (x-axis) - implying that for bubbles located more distant from the y-axis, the faster or the slower the corresponding creative industries grow in the past 10 -year period. 
- Relative concentration of the industry comparing to that of city average (using location quotient, the horizontal red line indicating $L Q=1$ on $y$-axis) - implying that for bubbles located more above from the red line, the more concentrated are the corresponding creative industries in Liberty Village compared with in the City.

Therefore, it is observed that while media industries continue to be the more concentrated and prominent creative sector in Liberty Village, advertising and creative-related computer services are two fast-growing substantial employment sectors in the area. This might be a result of the fact that besides a number of businesses present in the district, there is also a large number of national, provincial and regional-based non-government organizations in creative industries located in Liberty Village They include the Fashio: Design Council of Canada, Interactive Ontario, Computer Animation Studios of Ontario, Toronto Animated Image Society, Canadiar Recording Industry Association, and iiasion for Independent Filmakers of Toronto

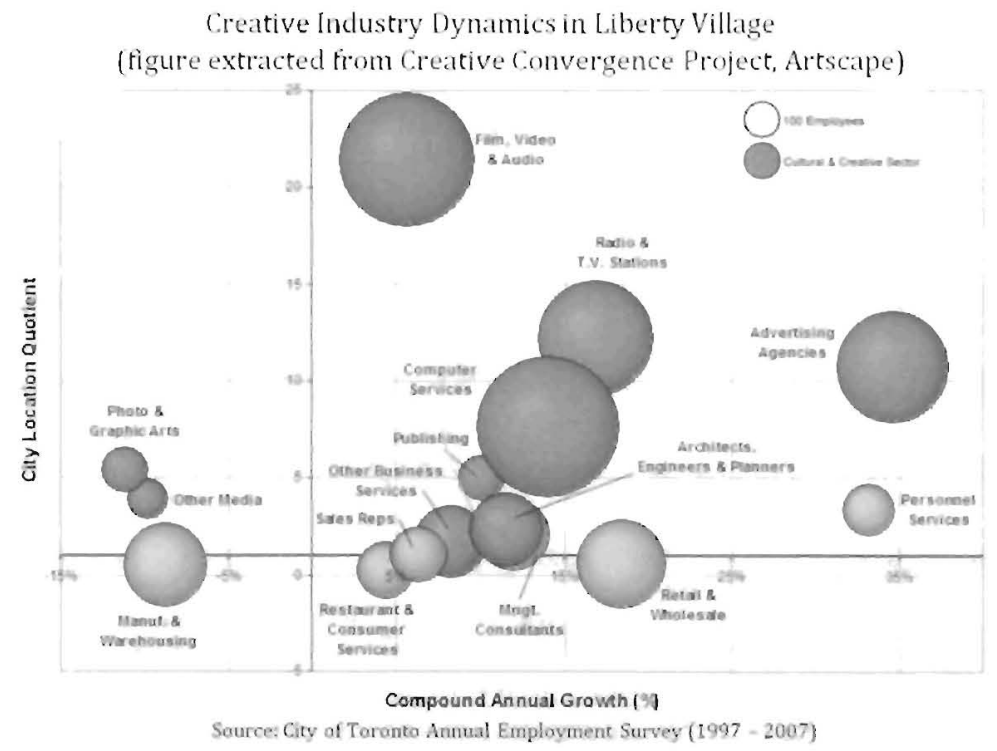




\subsection{Quality Places}

History provides Liberty Village with a rich architectural legacy of old, cultural industrial warehouses. Today, the City of Toronto is encouraging the conversion of existing buildings and restoration of those industrial buildings. As a result, the district has become an authentic urban precinct keep attracting creative workers with its non-traditional, stimulating, open office environments - particularly those new-media industries. Based on the historical information"1, the author took a walkabout in the district and obtained the following examples of quality places.

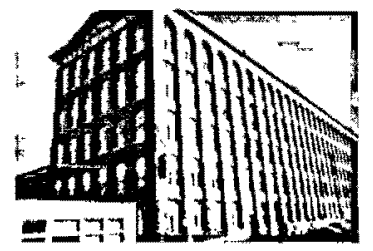

67 and 77 Mowat Avenue used to be the Toronto Carpet Factory between 1899 and 1920, later being purchased by the York Heritage Properties and converted into office and commercial use. Today when you step into this old industrial property, you will be impressed by how the reuse of this building has maintained the authenticity architectural attributes such as high ceilings, open windows, wooden floors, and sense of bricks and columns.

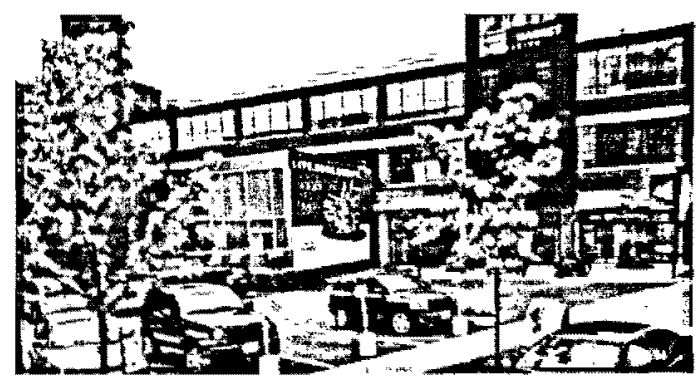

In 2003, Lifetime Urban Development Group purchased 171 East Liberty Street which used to be a machinery factory during late 1800 s, a gun manufacturing plant in early 1900s, and a home laundry product factory from 1950 to 1981 . It is currently converted into a retail and commercial complex - the Liberty Market Building.

\footnotetext{
11 All examples are generated based on the history information obtained from in Liberty village Toronto (httr://inlibertwillagecom/site) and Liberty Village BIA (http://wonolwbiasom).
} 


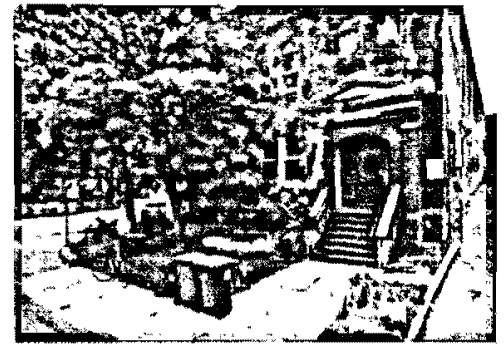

In 1991, Artscape acquired the building of 60 Atlantic Avenue a former historic winery - as their Head Office including 44 artist studios. This was a leading move that marks the emergence of an arts district in Liberty Village, and today Artscape continues to be an anchor for the community's artists.

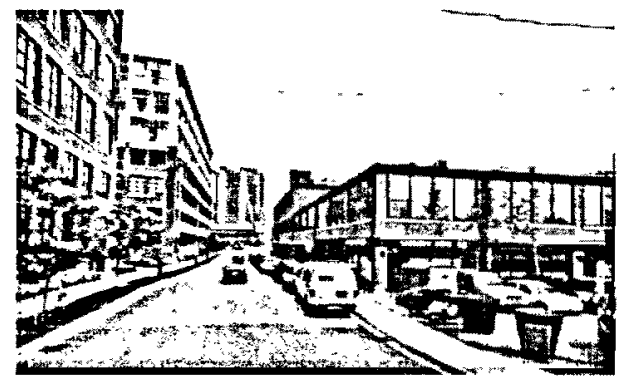

The building located on 99 Atlantic Avenue and 38 Hanna Avenue is post and beam structure built in 1890 and later became a factory that manufactured bowling alleys. Finally, the Academy of Spherical Arts opened on this site as a unique and high-class billiards and dining spot.

While being regenerated from a historic industrial warehouse district into today's host for creative workers involved in Interactive multi-media, radio and TV, information technology, and graphic design, Liberty Village is gradually being positioned as an area of certain identity and quality. As depicted in the first issue of the Liberty Village's newsletter: Liberty Village has been described as a funky mix of high tech and high art; non-conformist. Entrepreneurial, a different drummer, a highly creative, plugged-in business community (The Flame, 2002). Also, the district BIA places great attention on encouraging lifestyle amenities such as cafes and restaurants to accommodate creative workers' needs. 
More importantly, Liberty Village as a creative hub progresses as developing with a strong emphasis on networking and interaction. In a study conducted by Catungal et al. (2009) where a number of creative workers were interviewed, one owner of a design firm mentions:

It has been good for us because we have done a lot of work with our neighbours ... We have pretty much done design work for everyone in this hall and then other people in this building. There is a company upstairs that we do a lot of work for ... and also the property management is really good. They throw a lot of social events for the building.... Everyone from all the other floors comes down, mingles and meets everybody (p.1104).

\subsection{Planning \& Development}

The emergence of Liberty Village has largely benefited from the liberalized zoning framework for the adjacent King-Spadina area as facing dramatic decline in employment and recession in the early 1990s. Under the new flexible planning approach, synergy of uses and investment stimulation are particularly fostered. Accordingly, proper planning tools generate design authenticity for different mixed-used environments which eventually leads to the development and healthy maintenance of a creative hub like Liberty Village.

In the Toronto Official Plan, Liberty Village is designated as "Employment Area" on the Land Use Plan Map and "Employment Districts" on the Urban Structure Map which will be "protected and promoted exclusively for economic activity"12. Meanwhile, as part of the Garrison Common North Secondary Plan ${ }^{13}$, Liberty Village has been link with economic sectors that should be reinforced and any new economic activities will be encouraged. This is a significant move in generating healthy economic tractions that allow for the creative hub development. It is also

\footnotetext{
${ }^{12}$ See: http//www.toronto ca/involved/projects/kingston road ea/pdf/open-houses-mtl/p6 official plan maps.pdf ${ }^{13}$ See: http://www, torontoca/planning/official plan/pdf secondary/14 garrison common june 2006.pdf
} 
noteworthy that the Garrison Common North Secondary Plan has brought forward a live/work permission in Liberty Village by stating that "no residential use other than live/work units will be permitted" (p.6). This initiative seeks to maintain Liberty Village as an employment area, particularly targeting to protect the creative function of artist live/work studios. Mentioned in the Secondary Plan, artists live/work studios are defined as affordable units that must include work space. However, from the experience of dealing with a significant number of live/work units in the rest of the City are solely used as residential units with no employment or economic function, it is hoped that by preventing the encroachment of residential uses in the live/work studios in Liberty Village, more artists and creative workers can make use of the affordable working environment in the area.

Meanwhile, attracted by the low-rent and flexible industrial buildings units, pioneering artists and cultural advocates created a small influx into Liberty Village and established some concentrations of studios and live/work lofts during the 1980s. Also following the recognition of the importance of retaining and attracting more creative industries to this community, Artscape's entrance and its partnership with Toronto Economic Development Corporation in 1991 further enabled the beginning of the district becoming a creative hub for arts and cultural talents in the city. For instance, the project conducted by Artscape on the 60 Atlantic Avenue successfully turned a 30,000 square feet vacant industrial area into a creative precinct populated with artists and creative business, restaurants and lofts ${ }^{14}$.

Soon property owners in Liberty Village were given more freedom in determining commercial and office uses. Together with the unique architectural character in the area, small and large scale new media industries found their demands being satisfied in Liberty Village to work in a place where could best reflect their company culture at a financially affordable level.

${ }^{14}$ See: http://www.torontoartscape.on.ca/places-spaces/artscape-liberty-village 
In October 2001, the Liberty Village Business Improvement Area (LVBIA) was established by property and business owners as one of North America's First, also Canada's first non-retail Business Improvement Area (BIA) with a strong focus and interest of "developing a campus of creative spaces makes it truly unique"15. Also emphasized as one of the key missions in its latest strategic plan ${ }^{16}$, it aims at "promoting Liberty Village as an area to 'grow' any size of creative business and provide an environment that makes it easy to attract and retain the best and the brightest"(p.4).

To summarize, while the planning initiatives taken in Liberty Village are observed to be supportive and solid in recognizing the artistic strength and cultural ethos in the area which forms a sense of district identity, organizations such as Artscape and the Business Improvement Area (BIA) play important roles in provoking communication and discussion in building and promoting creative spaces in the district. In the case of Liberty Village, the changes in planning regulations enable the district to establish an encouraging and creative environment that satisfies one of the major premises in turning an area into a talent hub. Furthermore, organizational efforts that are invested undoubtedly serve as another planning driving force in realizing the emerging vision of the district as a creative hub. 


\section{REFLECTION AND CONCLUSION}

Urban creativity is a hybrid concept that leads to a highly mobilized and fluid environment. The emergence of creative hubs may sometimes occur in a spontaneous manner, however, planning initiatives and corresponding policies are very important in maintain the healthy development of its basic components: people and place. From recognizing talents as contributive knowledgeworkers to re-assessing its soft and hard infrastructures in attracting and facilitating them to innovate in the regional creative economy, a creative hub is regarded as a complex organic entity that requires cultivation and nurturing.

The creative-hub distribution analysis in Toronto provides a study with a grounded and solid perspective to observe the emergence of creative hubs. It is found that one outcome of districtlevel creative hubs in Toronto is urban regeneration. In particular, areas such as Liberty Village, Entertainment District, and the Distillery are engendered from changes in planning approaches that allow abandoned historic areas to naturally form affordable spaces, neighbourhood character and design authenticity under more flexible zoning regulations and encouraging planning programs. As for the institutional-level creative hubs that emerge around cultural and educational facilities, softer planning initiatives such as cultural planning establish an invisible conservatory for the benefit of their development.

Meanwhile, this study serves as a preliminary investigation of Toronto's creative-hub framework, and it reflects the need for more in-depth analysis on the interactive and linking relationships between creative hubs in the city region. The following three aspects are therefore suggested for future research. 


\section{Public realm}

During this study, an interview conducted with Ms. Lori Martin, Senior Cultural Affairs Officer from The Economic Development \& Culture Division (EDC) under the City of Toronto, brought up an interesting discussion on how public realm contributes to the lively linkages between creative hubs in Toronto. She points out that by preserving and promoting public arts and open spaces, district character can be continued and thus presenting natural connections between different cultural facilities and hubs. However, how to measure such public realm connection and define its effectiveness would require further exploration.

\section{Cultural mapping}

My research indicates that cultural mapping can provide useful perspectives in seeking interactions between creative hubs. Closely related to analyzing quality of life and social and economic vitality of municipalities, cultural mapping can examine and track different creative precincts from a broader angle and focusing on enhancing the larger area's well-being. Therefore, while mapping a range of cultural factors and urban resources, the collected information can also be used to determine the strength of relationships between creative hubs and therefore generate hypothesis and assumptions for addressing collective creative communication as well as collaboration deficiencies.

\section{Collaboration}

Compared with connection and networking, collaboration is a form of advancement of the mission of creative hubs and its performance could be rather intricate to observe and measure. However, the role of planning from the government should be emphasized as it possesses the capacity of acknowledging complexities of different contexts of collaboration (inter- and intrasector with inter- and intra- hub) and utilizing its pool of various resources available. 


\section{APPENDIX}

\section{Figure 1}

\section{LIBERT' VILLAGE EMPLOIXIENT DISTRICT LARGEST PRTATE SECTOR-NOX RETAIL EIIPLOITRS, 2007}

\begin{tabular}{|c|c|c|c|}
\hline Rauk & Company Name & Type of Business & Emplovinent \\
\hline 1. & Corus Entertainment (YTV) & $\begin{array}{l}\text { Integrated medis and entertainuent } \\
\text { company }\end{array}$ & $1,000^{-}$ \\
\hline 2. & Quality Meat Packers Ltd & International pork processing busimess & $500-999$ \\
\hline 3. & Nelvans & $\begin{array}{l}\text { International producers and distributors of } \\
\text { children's anumation and related consumer } \\
\text { products. }\end{array}$ & $300-499$ \\
\hline 4. & Softchoice & $\begin{array}{l}\text { Assisting customers to purchase and } \\
\text { manage their IT resources } r\end{array}$ & $300-199$ \\
\hline S. & Tucows Inc. & $\begin{array}{l}\text { Intemet senices company that provides } \\
\text { back office solutions and wholesale } \\
\text { intemet services to a global network of } \\
\text { more than } 6.000 \text { web hosting companies, } \\
\text { intemet service providers (ISPS) and other } \\
\text { senice providers worldwide. }\end{array}$ & $100-299$ \\
\hline 6. & $\begin{array}{l}\text { Canada Bread Company } \\
\text { limited }\end{array}$ & Bakery & $100-399$ \\
\hline 7. & Maxxium Canada & $\begin{array}{l}\text { Sales, local muktetng and distributton of } \\
\text { many of the world's premium spirits and } \\
\text { wine brands }\end{array}$ & $100-299$ \\
\hline 8. & The Marketing Store & ALukenng conmminications company & $100-299$ \\
\hline 9. & $\begin{array}{l}\text { Sony BMIG MLusic (Canada) } \\
\text { Inc. }\end{array}$ & Music production & $100-299$ \\
\hline 10. & The Strategic Coach & Business consuliants to entreprenelurs & $100-299$ \\
\hline 11. & Forrec Limited & $\begin{array}{l}\text { Design and planning of themed attractions, } \\
\text { environments and entertainment facilities. }\end{array}$ & $50-99$ \\
\hline 12. & S-Vox Inc. & $\begin{array}{l}\text { Provider of television and digital content } \\
\text { focused on spiritual awarevess and } \\
\text { personal growth and wellness. }\end{array}$ & $50-99$ \\
\hline 13. & Premiere Global Services, Inc & $\begin{array}{l}\text { Application of unfied communication } \\
\text { technology on demand }\end{array}$ & $50-99$ \\
\hline 14. & 9 Storey Entertainment Inc. & $\begin{array}{l}\text { Animanion, production and distribution } \\
\text { company }\end{array}$ & $50-99$ \\
\hline 15. & SIRILS Canada Inc. & Satellite radio station & $50-99$ \\
\hline 16. & Moveable Type Inc. & Corporate conmmancation projects & $50-99$ \\
\hline 17. & Labant Breweries of Canada & Admimistranion offices & $50-99$ \\
\hline 18. & Canadian Blood Sernces & Administration offices testung facility & $50-99$ \\
\hline 19. & Fuel Adiertising Sndio & Corporate advertising services & $50-99$ \\
\hline 20. & Net Present Services Lid. & On-line busmess consulting services & $50-99$ \\
\hline
\end{tabular}

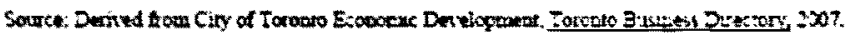




\section{REFERENCES}

Andrews, C. (2001). Analyzing quality-of-place. Environment \& Planning B: Planning \& Design, 28(2), 201.

Bell, D., \& Jayne, M. (2003). 'Design-led' urban regeneration: a critical perspective. Local Economy, 18(2),121-134.

Carta, M. (2007). Creative city: dynamics, innovations, actions. Barcelona: LISt Laboratorio.

Catungal, J., Leslie, D., \& Hii, Y. (2009). Geographies of displacement in the creative city: the case of Liberty Village, Toronto. Urban Studies, 46[5\&6), 1095-1114.

Clark, T., Lloyd, R., Wong, K., \& Jain, P. (2002). Amenities Drive Urban Growth. Journal of Urban Affairs, 24[5], 493-515.

Creative City Planning Framework - A Supporting Document to the Agenda for Prosperity for a Great City. (2008). AuthentiCity.

Crang, P. (1996). Displacement, consumption and identity. Environment and Planning, 28, 47-67. Combes, P. (2000). Marshall-Arrow-Romer Externalities and City Growth. CERAS working paper n99-06. Retrieved from: http://www.vcharite.univ-mrs.fr/PP/combes/note.pdf

Culture Plan for the Creative City. (2003). City of Toronto. Retrieved from:

http://www.toronto.ca/culture/cultureplan.htm

Curried, E. (2007). How art and culture happen in New York. Journal of the American Planning Association, 73(4), 454-465.

Donald, Betsy and Douglas Morrow, with Andrew Athanasiu. (2003). Competing for talent: implications for social and cultural policy in Canadian city-regions. A report prepared for Strategic Research and Analysis, Department of Canadian Heritage, Hull QC. 14 May.

Drucker, P. (1993). Post-capitalist society. New York: Harper Business

Eisebith, M. (2004). Innovative Milieu and Social Capital-Complementary or Redundant Concepts of Collaboration-based Regional Development? European Planning Studies, 12(6), 747-765. 
Evans, G. (2003). Hard-branding the cultural city: from Prado to Prada. International Journal of Urban and Regional Research, 27(2), 417-440.

Evans, G. (2009). From cultural quarters to creative clusters - creative spaces in the new city economy. Retrieved from:

http://cubastudies.org/londonmet/fms/MRSite/Research/cities/079cultural quarters and urban regeneration-090722-evans.pdf

Florida, R. (2000). "Competing in the age of talent: quality of place and the new economy" report prepared for the R.K. Mellon Foundation, Heinz Endowments, and Sustainable Pittsburgh, January, p. 29-30.

Florida, R. (2001). "The Entrepreneurial society" paper presented at the Conference on Entrepreneurship and Public Policy, Kennedy School of Government, Harvard University, April. Florida, R. (2002).The rise of the creative class: how it's transforming work, leisure, community and everyday life. New York: Basic Books.

Florida, R. (2003). Cities and the creative class. City and Community, 2(1), 3-17.

Florida, R. (2005). Cities and the creative class. London: Routledge.

Florida, R. (2008). Who's your city? New York: Basic Books.

Friedmann, J. (2007). The Wealth of Cities: Towards an Assets-based Development of Newly Urbanizing Regions.Development \& Change, 38(6), 987-998.

Garrison Common North Secondary Plan. Retrieved from:

http://www.toronto.ca/planning/official plan/pdf secondary/14 garrison common june2006. pdf

Gertler, M.S. (2001). "Urban Economy and Society in Canada: Flows of Ideas, People, and Capital." Isuma, (Autumn): 119-130.

Gertler, M. S. (2004). Creative cities: What are they for, how do they work, and how do we build them? Ottawa: Canadian Policy Research Networks.

Gertler, M.S., R. Florida, G. Gates \& T. Vinodrai. (2002). "Competing on Creativity: placing Ontario's Cities in North American Context" A report prepared for the Ontario Ministry of 
Enterprise, Opportunity and Innovation and the Institute for Competitiveness and Prosperity, November.

Gertler, M.S., Tesolin, L., \& Weinstock, S. (2006). Toronto Case Study. Toronto: Munk Centre for International Studies, University of Toronto.

Gibson, C., \& Kong, L. (2005). Cultural economy: a critical review. Progress in Human Geography, 29(5), 541-561.

Glaeser, E. L. (2005). Review of Richard Florida's The rise of the creative class. Regional Science and Urban Economics, 35, 593-596.

Glaeser, E. L., Kolko, J., \& Saiz, A. (2001). Consumer city. Journal of Economic Geography, 1, 27-50.

Hall, P. (1998). Cities in civilization. London: Weidenfeld.

Hall, T. and Hubbard, P. (Eds). (1998). The Entrepreneurial City: Geographies of Politics, Regime and Representation. Chichester: John Wiley and Sons.

Hanna, J., \& G., \& Baeker, G. (2009). Culture, authenticity, place: connecting cultural mapping and place branding. Municipal World. September Issue. p.9-12.

Hannigan, J. (1999). Fantasy City: Pleasure and Profit in the Postmodern Metropolis. New York: Routledge.

Hutton, T. (2009). Who's Your City? How the Creative Economy Is Making Where to Live the Most Important Decision of Your Life. Economic Geography, 85(3), 335-336.

Imagine a Toronto (2006) - Strategies for a Creative City. Retrieved from:

http://www.utoronto.ca/progris/imagineatoronto/fullReport.pdf

Jacobs, J. (1961). The Death and Life of Great American Cities. New York: Random House.

Kahn L., Ali, R., Buonfino, A., \& Leadbeater, C. (2009). Breakthrough cities: how cities can mobilize creativity and knowledge to tackle compelling social challenges. Retrieved from: http://creativecities.britishcouncil.org/

Kalden, P. \& Stolk, M. (2005). A practical view of creativity. In S. Franke \& E. Verhagen (Eds.), Creativity and the city: How the creative economy changes the city (pp.195). Rotterdam: NAi Publishers. 
Kloosterman, R., \& Trip, J. J. (2006). Planning for quality? Assessing the role of quality of place in developing high-speed railway stations. Paper presented at the International Conference on Urban Conditions and Life Chances, 6-8 July 2006, Amsterdam.

Kotler, P., Haider, D., \& Rein, I. (1993), Marketing Places. New York: Free Press.

Landry, C., Bianchini, F., Ebert, R., Gnad, R., \& Kunzmann, K. (1996). The creative city in Britain and Germany. London: Anglo-German Foundation for the Study of Industrial Society.

Landry, C. (2000). The creative city. UK: Earthscan.

Landry, C. (2006). The art of city making. UK: Earthscan.

Lynch, K. (1960). The Image of the City. Cambridge, MA: MIT Press.

Liberty Village Business Improvement Area. http://www.lvbia.com

Liberty Village Employment District Profile. (2007).Retrieved from:

http://www.toronto.ca/invest-in-toronto/pdf/ed profiles/Liberty Village.pdf

Liberty Village Area Study. (2006). Retrieved from:

http://www.toronto.ca/legdocs/mmis/2007/te/bgrd/backgroundfile-695.pdf

Lloyd, R. (2006). Neo-Bohemia: Art and commerce in the postindustrial city. New York: Routledge.

Markusen, A., \& King, D. (2003). The artistic dividend: The arts' hidden contributions to Regional Development. Minneapolis: University of

Minnesota, Humphrey Institute of Public Affairs Project on Regional and Industrial Economics.

Markusen, A. (2004). The distinctive city: Evidence from artists and occupational profiles. Minneapolis: University of Minnesota, Humphrey

Institute of Public Affairs Project on Regional and Industrial Economies.

Markusen, A. \& Schrock, G. (2006). The artistic dividend: urban artistic specialization and economic development implications. Urban Studies, 43(10): 1661-86.

Martin, P., Mayer, T., Mayneris, F. (2008). Natural clusters: why policies promoting agglomeration are unnecessary. Retrieved from: http://www.voxeu.org/

Martin, R. \& Florida. R. (2009). Ontario in the Creative Age. Martin Prosperity Institute. 
McNeil, D. (2007). Office buildings and the signature architect: Piano and Foster in Sydney. Environment and Planning, 39, 487-501.

Murray, G., \& Baeker, G. (2006). Culture + Place = Wealth Creation. Municipal World September Issue. p.13-16.

Nooteboom, B. (2006). Trust and Innovation. Essay written for the DutchMinistry of Economic Affairs, as background to the 2006Innovation Lecture on trust and innovation. Retrieved from: http://www.bartnooteboom.nl/EZTrust \%20and\%20innovation5.pdf

Paulsen, K. (2004). Making Character Concrete: Empirical Strategies for Studying Place Distinction. City \& Community, 3(3), 243-262.

Peck, J. (2005). Struggling with the creative class. International Journal of Urban and Regional Research, 29(4), 740-770.

Peck, J. (2007). Banal urbanism: cities and the creativity fix. Monu: Magazine on Urbanism,7,3547.

Porter, M. (2004). Location, Competition, and Economic Development: Local Clusters in a Global Economy. Economic Development Quarterly, 14[1]: 15-34.

Proter L, \& Barber, A. (2007). Planning the cultural quarter in Birmingham's Eastside. European Planning Studies, 15(10), 1327-1347.

Park, R., Burgess, E., and McKenzie, R. (1925). The city. Chicago, IL: University of Chicago Press.

Placing Creativity. http://placingcreativity.org/

Putting Arts and Culture on the Map: Literally! (2010). Hill Strategies Research Inc. Retrieved from: http://placingcreativity.org/media/MakingtheConnection/011-

PuttingArtsandCultureontheMap.pdf

Rutten, $\mathrm{P}$. [2005]. Creative industries and urban regeneration: findings and conclusions on the economic perspetctive, Urbact Network on Culture.

Saris, J. \& Brouwer, J. (2005). Creativity as competitive factor for urban regions. In S. Franke \& E. Verhagen (Eds.), Creativity and the city: How the creative economy changes the city (pp.195).

Rotterdam: NAi Publishers. 
Simon, C. (1998). Human capital and metropolitan Employment Growth. Journal of Urban Economics, 43, 223-243.

Staying Ahead: The economic performance of the UK's creative industries. (2007) The Work Foundation and National Endowment for Science, Technology and Arts. Retrieved from: http://www.theworkfoundation.com/research/publications/publicationdetail.aspx?oltemId=17 $\underline{6}$

Stern, M. J., \& Seifert, S. (in press). From creative economy to creative society. Progressive Planning.

Strategies for Creative Cities Project: Toronto Cast Study. (2006). Retrieved from: http://www.utoronto.ca/progris/imagineatoronto/Creative Cities Toronto Case Study.pdf Strenberg, R. (ed.). (1999). Handbook of Creativity. Cambridge: Cambridge University Press. Sweeney, G.P. (1987). Innovation, Entrepreneurs, and Regional Development. New York: St. Martin's.

Trip, J. (2007). Assessing quality of place. Journal of Urban Affairs, 29(5), 501-517.

The Convergence Centres - Building Capacity for Innovation. (2009). Creative Convergence Project, Toronto Artscape. Retrieved from:

http://www.torontoartscape.on.ca/research/creative-convergence-project

The Economy of Culture in Europe - a study prepared for the European Commission (2006). European Affairs. Retrieved from: http://www.ebu.ch/CMSimages/en/BRUDOC INFO EN 318 tcm6-48296.pdf

Toronto. (1995). New Directions for Physical Planning: The Three Lenses. Toronto: Planning and Development Department.

Toronto's Agenda for Prosperity. http://www.toronto.ca/prosperity/index.htm

Toronto Official Plan - Urban Structure Map. Retrieved from:

http://www.toronto.ca/involved/projects/kingston road ea/pdf/open-housesmtl/p6 official plan maps.pdf 
What makes a city great? Toronto 2010: Mayor David Miller's vision of a great city. Found at http://www.toronto.ca/mayor miller/pdf/miller platform webed screen.pdf

Vision 2011: Thinking Big about Culture-led Regeneration. (2009). Toronto Artscape. Retrieved from: http://www.torontoartscape.on.ca/about/vision2011 